\title{
Adeno-associated virus vector as a platform for gene therapy delivery
}

\author{
Dan Wang ${ }^{1,2,3,4}$, Phillip W. L. Tai ${ }^{1,2,3,4}$, Guangping Gao ${ }^{1,2,3,{ }^{*}}$ \\ ${ }^{1}$ Horae Gene Therapy Center, University of Massachusetts Medical School, Worcester, MA, USA. \\ ${ }^{2}$ Li Weibo Institute for Rare Diseases Research, University of Massachusetts Medical School, \\ Worcester, MA, USA. \\ ${ }^{3}$ Department of Microbiology and Physiological Systems, University of Massachusetts Medical \\ School, Worcester, MA, USA. \\ ${ }^{4}$ These authors contributed equally: Dan Wang, Phillip W. L. Tai
}

\begin{abstract}
Adeno-associated virus (AAV) vectors are the leading platform for gene delivery for the treatment of a variety of human diseases. Recent advances in developing clinically desirable AAV capsids, optimizing genome designs and harnessing revolutionary biotechnologies have contributed substantially to the growth of the gene therapy field. Preclinical and clinical successes in AAVmediated gene replacement, gene silencing and gene editing have helped AAV gain popularity as the ideal therapeutic vector, with two AAV-based therapeutics gaining regulatory approval in Europe or the United States. Continued study of AAV biology and increased understanding of the associated therapeutic challenges and limitations will build the foundation for future clinical success.
\end{abstract}

Adeno-associated virus (AAV) was first discovered from laboratory adenovirus (AdV) preparations in the mid-1960s $\mathrm{s}^{1,2}$ and found in human tissues soon after $^{3}$. Driven by pure scientific curiosity and without realizing its tremendous potential as a human gene therapy platform, a few research groups embarked on a journey to understand basic AAV biology ${ }^{4-6}$. During the first 15-20 years of AAV research, several important aspects of AAV were characterized, including its genome configuration and composition ${ }^{7-10}$, DNA replication and transcription ${ }^{11-13}$, infectious latency ${ }^{14-19}$ and virion assembly ${ }^{20}$. These achievements collectively fostered the successful cloning of the wild-type AAV2 sequence into plasmids, which enabled genetic studies ${ }^{21,22}$ and sequencing of the entire AAV2 genome ${ }^{23}$. These

\footnotetext{
* Guangping.Gao@umassmed.edu.

Competing interests

G.G. is a scientific co-founder of Aspa Therapeutics and Voyager Therapeutics and holds equity in the companies. G.G. is an inventor of patents related to adeno-associated virus (AAV) gene therapy with potential royalties licensed to Aspa Therapeutics, Voyager Therapeutics and other biopharmaceutical companies.

Publisher's note

Springer Nature remains neutral with regard to jurisdictional claims in published maps and institutional affiliations.

RELATED LINKS

ClinicalTrials.gov: http://www.clinicaltrials.gov/
} 
early investigations provided fundamental knowledge that led to the use of AAV as a gene delivery vehicle (FIG. 1). Since the advent of AAV vectors, their use as a biotherapy has also advanced our understanding of virus-host interactions that govern the transduction pathway of AAV (FIG. 2).

Today, recombinant AAVs (rAAVs) are the leading platform for in vivo delivery of gene therapies. The first rAAV gene therapy product, alipogene tiparvovec (Glybera), was approved by the European Medicines Agency to treat lipoprotein lipase deficiency in 2012 $\left(\mathrm{REF}^{24}\right.$ ), while the approval of voretigene neparvovec-rzyl (Luxturna), the first rAAV gene therapy product licensed in the United States, followed 5 years later. Although the clinical success of rAAV gene therapy is encouraging, we must acknowledge the limitations and challenges of this gene delivery platform, which include issues with rAAV manufacturing and immunological barriers to delivery ${ }^{25}$. These challenges are being addressed by a growing field that encompasses multidisciplinary expertise.

In this article, we aim to provide an overview of the use of AAV vectors to deliver therapeutic transgenes. We briefly introduce basic AAV biology and vectorology, describe general vector design principles and summarize current therapeutic strategies and clinical progress. Existing challenges, as well as recent advances that have helped to transition these promising drug platforms to the bedside, are discussed. While other viral and non-viral vectors have also played substantial roles in the advancement of gene and cell therapy, their discussion is beyond the scope of this article, and we refer readers to relevant review articles on these topics ${ }^{26-28}$.

\section{Fundamentals of AAV and vectorology}

\section{AAV as a virus}

AAV belongs to the genus Dependoparvovirus within the family Parvoviridae. Its life cycle is dependent on the presence of a helper virus, such as $\mathrm{AdV}$, hence its name and taxonomy classification. AAV is found in multiple vertebrate species, including human and non-human primates (NHPs). The current consensus is that AAV does not cause any human diseases. It is composed of an icosahedral protein capsid of $\sim 26 \mathrm{~nm}$ in diameter and a single-stranded DNA genome of $\sim 4.7 \mathrm{~kb}$ that can either be the plus (sense) or minus (anti-sense) strand ${ }^{29}$. The capsid comprises three types of subunit, VP1, VP2 and VP3, totalling 60 copies in a ratio of 1:1:10 (VP1:VP2:VP3). The genome is flanked by two T-shaped inverted terminal repeats (ITRs) at the ends that largely serve as the viral origins of replication and the packaging signal. The rep gene encodes four proteins required for viral replication; they are named after their molecular masses: Rep78, Rep68, Rep52 and Rep40. The cap gene encodes the three capsid subunits through alternative splicing and translation from different start codons. In addition, a third gene, which encodes assembly activating protein (AAP), is encoded within the cap coding sequence in a different reading frame and has been shown to promote virion assembly ${ }^{30,31}$. The AAV genome can integrate into a genomic locus known as AAVS1 in human cells to establish latency ${ }^{16-19,32-34}$. This phenomenon is in part due to the sequence similarity found within AAVS1 and the ITR and Rep activity. As discussed below, because rAAV is devoid of the rep gene, rAAV genome integration is greatly reduced. 


\section{$A A V$ as a vector for in vivo gene delivery}

In practical terms, rAAVs are composed of the same capsid sequence and structure as found in wild-type AAVs (wtAAVs). However, rAAVs encapsidate genomes that are devoid of all AAV protein-coding sequences and have therapeutic gene expression cassettes designed in their place. The only sequences of viral origin are the ITRs, which are needed to guide genome replication and packaging during vector production. The complete removal of viral coding sequences maximizes the packaging capacity of rAAVs and contributes to their low immunogenicity and cytotoxicity when delivered in vivo. The ITR-flanked rAAV genome can be cloned into plasmids and can be conveniently manipulated using standard molecular cloning techniques. Because rAAVs optimally accommodate genomes that are under $5.0 \mathrm{~kb}$ $\left(\right.$ REF $\left.^{35}\right)$, the payload must be carefully designed to consider not only the therapeutic transgene sequence but also the inclusion of regulatory elements necessary for gene expression (for example, promoter and polyadenylation signal).

It is now increasingly appreciated that host factors impacting the potency of gene delivery come into play as soon as the rAAV is administered to the patient. For example, new findings indicate that different serotypes interact with serum proteins in different ways ${ }^{36}$. Nonetheless, the effectiveness of rAAV is in large part determined by the molecular interactions between the capsid and target cell surface receptors 37,38 and subsequent downstream events following particle internalization ${ }^{39}$ (FIG. 2) The prevailing serotypes are presumed to recognize distinct cell receptors, such as glycoproteins, and therefore display different tissue-type and cell-type tropism profiles. Combinatorial recognition of coreceptors may also participate in cell surface binding and internalization ${ }^{39}$. AAVR was identified as an essential AAV receptor for multiple serotypes ${ }^{40,41}$. Intriguingly, AAVR may play a larger role in facilitating intracellular trafficking of the virus ${ }^{42}$. The receptorinteracting regions of several serotypes have been determined and collectively provide a roadmap for the rational engineering of capsids with desired properties ${ }^{43}$. Successful receptor recog nition may lead to internalization by endocytosis ${ }^{44-46}$. Intact rAAV particles in endosomes undergo a series of $\mathrm{pH}$-dependent structural changes necessary for transduction ${ }^{47}$ and traffic through the cytosol via the cytoskeletal network ${ }^{48}$. After endosomal escape, rAAV enters the nucleus through the nuclear pore complex ${ }^{49-51}$, where it undergoes capsid uncoating to release the genome. It is important to note that intracellular trafficking involves multiple cellular events and may abort at any step, resulting in unsuccessful gene delivery. Therefore, identifying the key cellular host factors and underpinning mechanisms that regulate this process holds great potential for improving rAAV transduction efficiency.

The single-stranded rAAV genome that is released in the nucleus is not immediately ready for gene expression until it is converted to a double-stranded form - a requirement of transcription and a rate-limiting step for transduction ${ }^{52,53}$ (FIG. 2). Second strand synthesis is initiated from the self-primed ITR at the $3^{\prime}$-end of the genome ${ }^{54,55}$. Additionally, doublestranded genomes can be achieved by strand annealing, whereby plus-stranded and minusstranded genomes that are packaged into separate virions anneal by Watson-Crick base pairing once in the nucleus ${ }^{56}$. An elegant rAAV genome design utilizes a mutated ITR to generate a self-complementary genome configuration, allowing for faster and higher gene 
expression than a conventional single-stranded AAV genome ${ }^{57,58}$. However, the packaging capacity is halved. The double-stranded genome then undergoes circularization via intramolecular or inter-molecular genome recombination at the ITRs ${ }^{59,60}$. This circularization and concatemerization process stabilizes the rAAV genome as episomal DNA, leading to gene expression that persists in postmitotic cells.

Replication and packaging of rAAV is dependent on host cell factors and elements provided by helper viruses, such as herpes simplex virus (HSV) and AdV. Therefore, cell-free systems for producing rAAV remain elusive given the present technologies. The development of methods to enhance rAAV production has been a continual challenge for human applications. Current platforms for $\mathrm{rAAV}$ production and purification are discussed in BOX 1 .

\section{Vector design \\ Capsid development}

The engineering of novel AAV capsids to gain new properties and characteristics has been a constant pursuit from the time when rAAVs were shown to exhibit clinical promise more than 20 years ago. Strategies for developing new capsids have evolved with technological advancements. For example, cryogenic electron microscopy (cryo-EM) has provided insights into the effect of structure and function of capsid residues on stability ${ }^{61}$ and how antibodies recognize and dock onto capsids ${ }^{62}$. This has accelerated the characterization and validation of new capsids. Capsid development approaches can be divided into three main categories: natural discovery, rational design and directed evolution (FIG. 3). With recent improvements to computational power and bioinformatic prediction methods, a new branch of AAV capsid design has emerged: in silico discovery. The pros and cons of these approaches and some seminal studies that exemplify the basis of these methods are discussed below.

Natural discovery.-As discussed above, AAV was originally discovered as a cell culture contaminant, as was the most widely characterized and used serotype, AAV2. Notably, the most clinically promising vectorized serotypes have been those that were isolated from natural sources. This notion is best epitomized by AAV9, which was isolated from human liver tissue ${ }^{63}$. AAV9 is a clade F serotype and demonstrates the capacity to bypass the blood-brain barrier (BBB), making it a leading capsid for the transduction of the central nervous system (CNS) via systemic administration. Livers and spleens are the predominant sites of natural AAV infection in both humans and NHPs, although proviral sequences can be isolated from a range of tissues ${ }^{63-67}$. For instance, other human-derived clade F capsids that have recently gained attention are those isolated from CD34+ human peripheral blood haematopoietic stem cells, which demonstrate the capacity to confer nuclease-free gene editing ${ }^{68,69}$.

Epidemiological analyses have shown that $40-80 \%$ of the human population are seropositive for antibodies against $\mathrm{AAV}^{70}$, suggesting that human-derived capsids may not be ideal for gene therapy vectors owing to pre-existing AAV capsid immunity that may reduce transduction efficacy. seroepidemiological and molecular studies indicate that AAV1, AAV2, 
AAV3, AAV5, AAV6, AAV7, AAV8 and AAV9 are endemic to humans ${ }^{63,71-75}$. Therefore, isolation of capsids from non-human sources may overcome pre-existing immunity. Capsids isolated from NHPs have thus far shown substantial promise, and NHP-derived AAVrh.8, AAVrh.10 and AAVrh.43 (clade E capsids; AAV8 is also a member) have been shown to transduce a range of tissues. However, the prevalence of anti-AAV8 neutralizing antibodies (NAbs) in the human population ranges from $10 \%$ to $40 \%$ depending on geographical sampling ${ }^{73}$. Other clade E capsids may therefore exhibit reactivity despite their promise.

Alternatively, many studies have now focused on the promise of AAV capsids that are isolated from other vertebrate species ${ }^{76-83}$. Although these capsids have the lowest theoretical chance of eliciting a pre-existing immune response in patients, they may also exhibit lower transduction profiles in humans. Notably, porcine-derived rAAVs were reported to transduce mouse organs with efficiencies contending with gold-standard $\mathrm{AAVs}^{84}$. Most promising of all, porcine AAVs were shown to not be neutralized by pooled human immunoglobulin $\mathrm{G}(\mathrm{IgG})$ and have the capacity to transduce the adult mouse brain, suggesting that these vectors can bypass the BBB.

With advances in high-throughput sequencing methodologies, the discovery of natural capsid diversity has become simplified. Long-read sequencing technologies such as single molecule, real-time (SMRT) sequencing allows for the sequencing of full-length proviral genomes without the need for sequence reconstruction ${ }^{85}$. Because multiple AAV serotypes have been observed in tissue biopsy samples from individual patients, this technology provides the ability to observe variants as a consequence of natural recombination between several AAV genomes ${ }^{86}$.

Rational design.-Among the first approaches to improve vector capsids was engineering by rational design. Such strategies began with simple grafting of peptide sequences that bind to cell-type-specific receptors ${ }^{87}$. Introduction of integrin-binding peptide sequences onto the surface of the capsid resulted in the re-targeting of AAV2 to cells resistant to infection ${ }^{88}$. Other methods employed the fusion of peptide sequences onto the amino terminus of VP2 $\left(\right.$ REF $\left.^{89}\right)$, such as the single-chain variable fragments ( $\left.\mathrm{scFvs}\right)^{90}$ and designed ankyrin repeat proteins (DARPins) ${ }^{91}$, to confer antibody-like recognition to cell surface markers.

Alternatively, it is widely regarded that the 3-fold protrusions play important roles in shaping the tropism profile and immunogenicity of the capsid, therefore making the exposed position of the 3 -fold protrusion an ideal position for peptide insertion to augment receptor binding. Such approaches not only can retarget capsids but also have the capacity to deter immunological recognition. For example, the engineered AAV2i8 capsid not only detargets from the liver for increased skeletal and cardiac muscle transduction but also has the added benefit of an altered antigenic profile ${ }^{92}$. Notably, the first engineered vectorized capsid used in a clinical trial, AAV2.5, was designed rationally ${ }^{93}$. This capsid, which exhibited improved muscle transduction, was developed by transferring five amino acids from AAV1 onto the AAV2 capsid scaffold.

Although rational modification to capsid structure may improve tropism, it may also negatively impact other characteristics of the capsid, such as its stability. The introduction of codon expansion and click chemistry allows modification of capsids after virion assembly. 
By taking advantage of the pliability of the 3-fold protrusion, click chemistry amino acid modifications show exemplary ability to alter capsid function without impacting assembly and packaging ${ }^{94-97}$.

Another means of improving vector transduction through rational design is to disrupt cellular degradation of capsids. Site-directed mutagenesis of surface-exposed tyrosine residues was shown to increase murine hepatocyte transduction by nearly 30 -fold via the inhibition of proteasomal degradation and facilitation of intracellular trafficking ${ }^{98}$.

Despite the introduction of high-throughput screening methods (discussed below), rational design will always have a place in the engineering of novel vectors. For example, the recently reported AAV2 true-type (AAV-TT) capsid was designed by combining conserved residues identified among natural AAV2 variants from children who were seropositive for AAV2 (REF. ${ }^{99}$ ). AAV-TT was found to exhibit increased thermal stability compared with AAV2 and, importantly, to have favourable CNS transduction in mice ${ }^{99}$. Notably, AAV-TT also lacks the heparan sulfate proteoglycan (HSPG) binding motif, which serves as the binding site for AAV2 and presumably is a result of the adaptive selection of AAV2 in cultured cells. High expression levels of HSPG in the extracellular matrix lead to reduced spread and sequestration of AAV2 in off-target tissues, limiting the therapeutic efficacy of AAV2 when delivered systemically. Although AAV-TT lacks the ability to cross the BBB, it represents a rationally designed capsid that may have usefulness for treatments requiring intraparenchymal vector administration.

Elucidation of the structure-function relationships among several AAV capsids provides important clues for rational engineering. Guided by this structural information, a natural AAV9 capsid variant was isolated from chimpanzee tissues that differs from prototypical AAV9 by four residues, two of which reside at the 3-fold protrusion. When these two residues are mutated on AAV9, the engineered capsid, called AAV9.HR, greatly detargets from peripheral tissues but retains the capacity of AAV9 to cross the BBB following intravascular injection in neonatal mice ${ }^{100}$. In another study, several capsid antigenic motifs (CAMs) clustered at the 3-fold symmetry axis were identified by analysing the cryoreconstruction data of AAV1-NAb complexes ${ }^{101}$. The authors evolved the residues within these motifs and obtained a synthetic capsid named CAM130, which demonstrated reduced NAb recognition compared with the parental AAV1 capsid. Despite the promise of these rationally designed capsids revealed by mouse models, further comparative analyses for these and any newly engineered capsids are required in large animal models before moving to clinical testing.

Directed evolution.-A major limitation to rational design approaches is related to insufficient knowledge pertaining to AAV cell surface binding, internalization, traffic king, uncoating and gene expression. Therefore, de novo approaches to discovery, namely, directed evolution strategies, are favourable in many instances ${ }^{102-108}$. The basis of directed evolution is rooted in the simulation of natural evolution, whereby capsids are under selective pressure to yield genetic variants with specific biological properties and advantageous characteristics (for example, tissue-specific targeting, immunological evasion and transgene expression). Therefore, directed evolution of capsid libraries does not require 
prior understanding of the molecular mechanisms involved in the selection criteria. For example, iterative rounds of in vitro selection with a library of peptide sequences embedded at the 3-fold protrusion has yielded capsids with remarkable redirected tropisms ${ }^{109,110}$.

Alternatively, error-prone PCR at discrete regions or throughout the entire cap gene is also a viable means of generating capsid libraries for screening ${ }^{103}$. Many recent studies have also utilized the randomized generation of chimeric capsids (capsid shuffling) from the primary sequences of pre-existing serotypes ${ }^{106-108,111}$. In combination with error-prone PCR, capsid shuffling can achieve a higher diversity of capsid libraries by surveying a wider palette of pre-existing capsids with inherently different tropism profiles ${ }^{112,113}$. Notably, rAAVs that preferentially target HIV-1-infected H9 T cells have recently been evolved ${ }^{114}$.

A notable directed evolution method is Cre recombination-based AAV targeted evolution (CREATE $)^{110}$. This methodology, which also employs the insertion of a randomized peptide fragment into the 3-fold protrusion, relies on Cre recombination to repair an inverted polyadenylation sequence designed into the vector genome. Because Cre recombination requires a double-stranded DNA target, only capsids that can mediate efficient intracellular trafficking and conversion of the single-stranded viral genome to the double-stranded form within the nucleus can be processed by Cre recombinase in Cre-expressing cells. This method led to the identification of AAV-PHP.B and other capsid variants that can cross the BBB to transduce the $\mathrm{CNS}^{110,115}$.

With the advent of next-generation sequencing approaches, directed evolution has become an even more powerful technique for the discovery of novel vector capsids. The ability to screen several thousand barcoded transgenes allows for the iterative enrichment of candidates that can transduce cell or tissue types. The only true limitation for these techniques is that the evolution of capsids needs to be performed in a model that best mimics the intended target tissue. For instance, in vitro-directed evolution of AAV does not simulate crossing blood-organ barriers after vascular administration. Therefore, in vivo screening of capsid libraries is highly preferred. Unfortunately, not all in vivo models are created equal. Preclinical rAAV discovery and validation, on the whole, have been performed in animal models that recapitulate neither AAV tropism in humans nor the vector potency required for therapeutic efficacy. For example, AAV-PHP.B was shown to not outperform AAV9 in the CNS of large animal models ${ }^{116-118}$. These outcomes may be rooted in the model system that was used for its discovery. Because evolving capsids in humans is not feasible, humanized mouse models are the best surrogates for these investigations. For example, using AdV5mediated viral selection in $\mathrm{Fah}^{-/-} \mathrm{Rag}^{-/}{ }^{-} \mathrm{Il}_{2} \mathrm{rg}^{-/-}$(FRG) mice that are partially repopulated with primary human hepatocytes can effectively achieve the identification of capsid vectors that are specific to human liver cells ${ }^{102}$.

In silico bioinformatic approaches.-Structural constraints imposed by secondary, tertiary and quaternary interactions within and between monomers add to the layer of complexity when evaluating mutagenesis outcomes within understudied capsid domains. The use of computational tools has greatly improved vector design approaches without the need for complete understanding of AAV capsid biology. For example, in conjunction with high-throughput sequencing, bioinformatic tools can be employed for the design of capsid variant libraries to identify high-variability regions that tolerate manipulation ${ }^{119}$. Indeed, in 
silico methods for novel capsid engineering have gained recent attention. For example, by using in silico phylogenetic and statistical modelling of known capsid sequences to infer evolutionary intermediates, ancestral capsid sequences have been predicted ${ }^{120}$. This work resulted in the discovery of Anc80, which shows promising efficacy in mouse liver, skeletal muscle, retina and cochlea ${ }^{120,121}$. Similarly, in silico sequence analysis of germline endogenous viral elements (EVEs) among several marsupial species revealed fossilized viral integration events within host DNA ${ }^{122}$. These EVEs were characterized and reconstructed as novel ancestral capsids with potentially desirable vector properties.

\section{rAAV genome design and engineering}

The typical rAAV genome design carries a gene expression cassette, which includes a promoter, a transgene and a transcription termination signal. Together, these components serve the main function of expressing therapeutic levels of gene product once the vector is delivered to the target cell nucleus. Design of the gene expression cassette is tailored to suit the specific requirements of the therapy (for example, transgene expression level, tissue-type and cell-type specificity and packaging size limitations). In addition, DNA-based regulatory elements are being developed to address potential undesired effects such as loss of vector in proliferating cells. This section discusses basic rAAV genome design and engineering. It should be noted that when designing efficacious rAAV vectors, the synergy between the capsid and the genome must also be considered. A combinatorial design approach that marries capsid and vector genome features and characteristics is ultimately needed to develop successful rAAV platforms to treat human disease.

Controlling transgene expression level and specificity.-In many cases, rAAV gene therapy platforms utilize a strong and ubiquitous promoter to achieve high transgene expression. Such promoters include the cytomegalovirus (CMV) promoter and the chicken $\beta$-actin promoter fused with the CMV enhancer. Other regulatory elements can also enhance gene expression, such as an intron ${ }^{123,124}$ and the woodchuck hepatitis post-transcriptional regulatory element (WPRE) ${ }^{125,126}$. Although the WPRE was shown to promote tumorigenesis ${ }^{127}$, a modified version shows a much safer profile ${ }^{128}$. For gene expression in human cells, even wild-type human-derived gene sequences are not necessarily optimized to yield robust protein expression. This is in part because a natural sequence may not fully utilize the most preferred codon for an amino acid residue. In addition, elements of the transgene sequence itself, such as GC content, cryptic splice sites, transcription termination signals, motifs that affect RNA stability and nucleic acid secondary structures, can impact on expression. Therefore, codon optimization is widely used in rAAV gene therapy aiming to enhance gene expression ${ }^{129-132}$. At the translational level, inclusion of a Kozak sequence can further increase protein expression ${ }^{130}$. To drive the expression of small RNA molecules such as short hairpin RNAs (shRNAs) and single-guide RNAs (sgRNAs), the human or murine U6 small nuclear RNA promoter and human $\mathrm{H} 1$ promoter are commonly used ${ }^{133}$.

It is important to note that high transgene expression levels are not always preferred. Supraphysiological expression of a protein or RNA molecule may be toxic. This has proved to be a critical consideration for delivering the genes encoding MECP2 ${ }^{134,135}$ and hexosaminidase ${ }^{136}$ for treating Rett syndrome and GM2 gangliosidosis, respectively. 
Similarly, shRNA expression that is driven by the strong U6 promoter is associated with toxicity owing to saturation of the endogenous microRNA (miRNA) biogenesis pathway ${ }^{137}$, which can be ameliorated by using a weaker $\mathrm{H} 1$ promoter. Alternatively, new platforms based on the expression of artificial microrNAs (amiRs) by Pol II promoters provide a more versatile solution for RNA interference (RNAi) ${ }^{138-142}$.

Expression specificity is another important aspect of gene therapy. Gene expression in offtarget tissues or cell types may lead to toxicity or trigger an unwanted immune response (see below). From the rAAV genome design perspective, prominent strategies that better confine gene expression in desired compartments include using tissue or cell type-specific promoters ${ }^{130,143}$ and incorporating miRNA binding sites in the $3^{\prime}$-untranslated region (UTR) to detarget expression from cells that are enriched for the miRNA ${ }^{144-147}$. One notable application of such a detargeting strategy concerns professional antigen-presenting cells (APCs) that harbour a high level of miR-142-3p. The inclusion of miR-142-3p binding sites in vector cassettes was shown to efficiently diminish transgene expression in APCs and greatly reduce immunity against the transgene product ${ }^{148,149}$.

Accommodating large transgenes.-One limitation of AAV vectors is their small packaging size $(\sim 5.0 \mathrm{~kb}$, including ITRs) compared with other viral vectors. However, several strategies have been investigated to enable delivery of a large therapeutic gene. A seemingly straightforward workaround is to design a shortened version of the gene that encodes a truncated but functional protein. One example involves the development of a micro-dystrophin gene replacement therapy for Duchenne muscular dystrophy (DMD) ${ }^{150}$. The entire coding sequence of the human dystrophin gene is $11.5 \mathrm{~kb}$, well exceeding the packaging limit of rAAV. A landmark study demonstrated that a half-sized protein is partially functional and associated with an attenuated muscular dystrophy phenotype ${ }^{151}$. Further studies on the structure and function of dystrophin led to the generation of several smaller forms that can be packaged within AAV vectors ${ }^{150}$. Development of a micro-gene that is amenable to rAAV delivery likely requires a deep understanding of the structurefunction relationship of the protein and is therefore gene-specific. Nevertheless, micro-gene therapy is under extensive clinical evaluation for $\mathrm{DMD}^{150}$ and preclinical testing for dysferlinopathy ${ }^{152}$ and CEP290-associated Leber congenital amaurosis (LCA) ${ }^{153}$.

A potentially promising approach for delivering oversized transgenes in rAAVs is to coadminister two AAV vectors that carry separate halves of a gene ${ }^{154-158}$. The two vector genomes can undergo inter-molecular recombination once co-delivered into the same cell, allowing for the reconstitution of the full-length gene. The ITR or an optimized recombinogenic sequence can serve as the overlapping sequence between the two vector genomes to promote recombination ${ }^{154,159-161}$. A key feature of such a dual-vector design is the utilization of splicing signals flanking the overlapping sequence, which ensures the precise removal of the recombinogenic sequence from the pre-mRNA during splicing. Analogous to mRNA splicing, intein-mediated protein trans-splicing (PTS) precisely fuses two peptides carrying a split intein ${ }^{162}$. Reconstitution of a full-length protein by PTS has been demonstrated for dystrophin ${ }^{163}$ and Cas9 (REFS ${ }^{164,165}$ ), a programmable endonuclease widely used for gene editing. While the micro-gene strategy has progressed into clinical testing and shows promising early results ${ }^{150}$, the dual-vector and PTS approaches remain 
under preclinical development. The reconstitution efficiency is one bottleneck that limits broader application. Optimizing the overlapping sequence to promote efficient recombination and engineering split inteins to allow for efficient PTS will greatly facilitate their translational use.

Enhancing persistence.-Although rAAVs are a favourable vector for gene therapy, they persist as non-replicating episomes. Transduced vector genomes are therefore gradually lost in mitotic cells. Strategies for retaining transgene expression in replicating cells have been sought. The most straightforward approach to achieving prolonged transgene expression in replicative cell types is the promotion of rAAV genome integration. As discussed in BOX 2, rAAV genomes are found to integrate at low frequencies. Such rare and unsupervised integration events usually result in partial genome integration and are therefore not ideal for therapeutic purposes.

Gene editing provides a promising solution to enhance persistence through targeted genomic integration. Once a programmable nuclease introduces DNA breaks in the target genomic locus, the homology-directed repair (HDR) pathway of the host cell can use the rAAV genome as a donor template, resulting in the precise and heritable insertion of a therapeutic gene cassette into the host genome ${ }^{166}$. If the nuclease is also directed to cleave the rAAV genome, the liberated double-stranded linear DNA fragment carrying the therapeutic gene cassette can be inserted into the targeted genomic locus by homology-independent targeted insertion ${ }^{167,168}$. In addition, nuclease-free homologous recombination-directed integration has recently gained attention as an alternative approach for gene editing $69,169,170$. This phenomenon works by inserting flanking segments of sequence that are homologous to genomic target sites into vector genomes ${ }^{171}$. In this way, stable integration of sequences can be achieved without the need to introduce DNA breaks via a nuclease.

Alternatively, strategies to allow vector persistence via insertion of scaffold/matrix attachment region (S/MAR) sequences into constructs so that episomal forms can undergo replication in transduced cells have been explored ${ }^{172}$. The use of S/MARs in plasmid constructs has been utilized for long-term gene expression over hundreds of cell doublings ${ }^{173}$.

\section{Translational applications}

As of 13 November 2018, there were 145 interventional clinical trials involving rAAV registered at ClinicalTrials.gov (FIG. 4). To date, there are two vectorized AAV serotypes that have gained regulatory approval for commercial use in patients: AAV1 (Glybera; uniQure) and AAV2 (Luxturna; Spark Therapeutics). There are less than a dozen capsid serotypes that are currently used as vectors in clinical trials, the most numerous being AAV2-based platforms. However, newer and more efficient capsids, such as AAV8, AAV9 and AAVrh.10 are increasingly being utilized in trials. In most cases, the therapeutic strategy involves the targeting of a monogenic recessive disease by gene replacement (TABLE 1). Phase I/II trials are commonly carried out to expedite the product development for rare genetic diseases with fewer patients. A selection of ongoing interventional clinical trials can 
be found in TABLE 1. Some exemplary translational applications and successes are discussed below in the context of target tissues and therapeutic strategies.

\section{Target tissues amenable to rAAV gene delivery}

Considering the natural tropism of AAV and unmet medical needs, most rAAV gene therapy programmes focus on the liver, striated muscles and the CNS. Almost all natural AAV capsids can transduce liver efficiently following systemic administration. Thus, rAAVs provide a robust liver-targeting platform to treat a variety of diseases such as haemophilia A and haemophilia B, familial hypercholesterolaemia, ornithine transcarbamylase deficiency and Crigler-Najjar syndrome ${ }^{174}$. Capsids such as AAV8 and AAV9 can target multiple muscle types throughout the body, enabling rAAV gene therapies to be developed for multiple muscle diseases ${ }^{175}$, especially those afflicting muscles of the entire body, such as DMD. Notably, transduced muscle can serve as a bio-factory to produce secreted therapeutic proteins for the treatment of non-muscle diseases. Although most heart diseases are polygenic and influenced by environmental factors, several genes involved in signalling and metabolism have been tested to treat heart failure ${ }^{176}$.

A large percentage of rAAV gene therapy under clinical development is focused on the CNS, including the brain ${ }^{177,178}$ and eye $\mathrm{e}^{179-181}$. The eye is a somewhat confined and compartmentalized organ that is amenable to direct ocular rAAV gene delivery. Notably, the first rAAV gene therapy drug approved by the US Food and Drug Administration (FDA), Luxturna, treats patients with an inherited form of vision loss caused by RPE65 gene mutations ${ }^{182}$. By contrast, the brain is much more complex and larger. Direct intraparenchymal rAAV injections result in localized distribution of rAAV and are ideal for the treatment of CNS diseases that afflict a defined region of the brain, such as the putamen in Parkinson disease. Delivery to the cerebrospinal fluid space by intrathecal injection, on the other hand, can achieve broader CNS distribution. Unfortunately, these routes of administration can be invasive and pose substantial risks. Alternatively, intravenous delivery of certain serotype vectors, such as AAV9 and AAVrh.10, has allowed the vectors to cross the BBB to transduce neurons and glia ${ }^{183-186}$. This landmark discovery led to a number of studies demonstrating the therapeutic efficacy of systemic rAAV administration to target diseases that afflict widespread regions of the CNS, including spinal muscular atrophy (SMA) ${ }^{187}$, amyotrophic lateral sclerosis ${ }^{140,188,189}$, Canavan disease ${ }^{130,190}$, GM1 gangliosidosis ${ }^{191}$ and mucopolysaccharidosis type $\mathrm{III}^{192}$. Multiple clinical trials that utilize this powerful rAAV platform are currently underway ${ }^{193}$.

\section{AAV gene therapy strategies}

Gene replacement.-This strategy aims to deliver a gene product to compensate for lossof-function mutations. Gene replacement is suitable for treating recessive monogenic diseases and has enjoyed the most clinical success, as demonstrated by Glybera and Luxturna. Glybera is a rAAV1-based platform that delivers a hyperactive form of the gene encoding lipoprotein lipase (LPL) to treat LPL deficiency ${ }^{194}$. The benefit of using a hyperactive variant is that vector potency is increased, enabling a reduction in the vector dose. This not only eases manufacturing burdens but also reduces capsid immunity, as discussed below. Luxturna is an AAV2-based platform that delivers an RPE65 gene cassette 
to treat retinal dystrophy caused by biallelic mutations in RPE65 (REF. ${ }^{182}$ ). Both Glybera and Luxturna are administered locally to the muscle and eye, respectively. AAV vectors derived from AAV1 and AAV2 are still being pursued in some clinical studies aiming to deliver transgenes locally to the muscle, eye or brain (TABLE 1). However, both capsids have limited capacity to achieve widespread gene delivery following systemic injection.

In the early 2000s, the discovery of a novel family of naturally occurring primate AAV serotypes and variants greatly expanded the toolbox of capsids to achieve much more widespread transgene delivery following intravascular injection ${ }^{63,64}$. Several ongoing gene replacement clinical trials take advantage of these newer capsids and have demonstrated promising therapeutic outcomes, including trials for haemophilia A and haemophilia B (targeting liver), DMD (targeting whole body muscle) and SMA (targeting the broad CNS, including the spinal cord) (TABLE 1). Restoration of protein production at a fraction of normal physiological levels can in many cases alleviate the disease. In many disorders, the delivery of functional transgenes to only a subset of cells within an affected tissue is sufficient.

Gene silencing.-In contrast to gene replacement, gene silencing mainly tackles monogenic diseases caused by gain-of-toxicity mutations, such as Huntington disease. Owing to their potency for inhibiting gene expression, RNAi strategies currently dominate rAAV-based gene silencing platforms. However, compared with the rapidly advancing synthetic RNAi therapeutics, rAAV-based RNAi therapies mostly remain under preclinical develop ment ${ }^{195}$. Gene silencing often has to occur with high tissue penetrance to achieve meaningful therapeutic outcomes, a challenge for AAV vectors with certain target organs, such as the human brain. In addition, high levels of Pol III-driven shRNAs may overwhelm the endogenous miRNA biogenesis pathway, leading to toxicity ${ }^{137}$. Off-target silencing by RNAi is another safety concern. Although embedding shRNAs in an amiR scaffold that is transcribed by a Pol II promoter can significantly reduce off-target silencing, as well as generate tolerable amounts of small interfering RNA (siRNA) molecules ${ }^{138-142}$, RNAi efficacy may be reduced. Regardless of how the shRNA is constructed and expressed, the short hairpin DNA structure that encodes the shRNA was recently shown to cause truncated rAAV genomes during vector production and can compromise vector genome homo geneity ${ }^{196}$. Interestingly, engineering pri-miR-33 to express siRNAs not only improves rAAV genome integrity but also reduces toxicities associated with off-target silencing and/or saturation of endogenous RNAi machinery ${ }^{197}$. Importantly, amiRs derived from the primiR-33 scaffold have RNAi efficacies that are comparable to Pol III-driven shRNAs ${ }^{197}$.

In addition to RNAi, the recently reported Cas 13 family of proteins provides another means to silence gene expression at the mRNA level ${ }^{198,199}$. These proteins possess potent RNAguided ribonuclease activity and appear to be more specific than RNAi. At the transcriptional level, gene expression can be silenced by a CRISPR-Cas9 repressor delivered by dual AAV vectors ${ }^{200}$. However, the translational uses of CRISPR-Cas will face several obstacles including rAAV packaging size limitations and immune responses against the bacteria-derived foreign protein ${ }^{165,201,202}$. 
Gene addition.-Beyond monogenic diseases, rAAV-mediated gene therapy has the potential to tackle complex genetic diseases and acquired diseases by gene addition. Human diseases, such as heart failure and infectious diseases, represent some of the most urgent unmet medical needs. Gene addition can modulate these diseases in multiple ways, such as supplying neurotrophic factors for neurological diseases ${ }^{177}$ and tuning signalling pathways for heart failure ${ }^{203}$ and cancer ${ }^{204}$. A notable gene addition strategy employs rAAV delivery of genes encoding recombinant antibodies that can neutralize deadly viral infections ${ }^{205-210}$. These platforms utilize intramuscular delivery and transform the transduced muscle cells into a bio-factory to produce therapeutic antibodies that are secreted into the bloodstream. This strategy is currently being tested clinically for HIV infection (TABLE 1). One challenge is the mounting of immunity against the vectored antibodies, as they can be recognized as foreign proteins. This anti-antibody response can suppress the circulating antibody concentration below the targeted threshold, limiting efficacy. rAAV-related immune responses are further discussed below.

Gene editing.-The rapidly evolving gene-editing technologies provide a versatile toolbox to directly repair mutations underlying human diseases. Therapeutic gene editing typically occurs in two steps: generation of targeted DNA breaks in the genome and DNA repair that eventually leads to a desired DNA alteration.

A series of programmable nucleases has been developed to generate DNA breaks, such as engineered meganucleases, zinc-finger nucleases (ZFNs), transcription activator-like effector nucleases and CRISPR-associated (Cas) proteins. ZFNs are tolerable because they are derived from human proteins, and their small transgene sizes are amenable to rAAV packaging. In contrast to ZFNs, the Cas proteins are derived from bacteria, such that their immunogenicity is a potential roadblock for rAAV gene delivery. In addition, their large cDNA sizes make rAAV delivery less flexible. Nevertheless, the Cas proteins are a robust gene-editing system that can be easily programmed to target a specific genomic DNA locus and remain the most extensively studied programmable nucleases for both research and therapeutic applications.

The main cellular DNA repair pathways leading to therapeutic gene-editing outcomes include non-homologous end joining (NHEJ) and HDR, and they are usually exploited to introduce gene disruptions and precise corrections, respectively. In addition to delivering the nuclease transgene, the single-stranded rAAV genome can also serve as a donor template to enable HDR. The synergistic effects of sequence-specific nucleases and DNA repair mechanisms can yield many therapeutic gene-editing approaches beyond disrupting a gene by NHEJ ${ }^{211-213}$ and directly repairing a mutation by $\mathrm{HDR}^{166,214-217}$. For example, the first in vivo rAAV gene-editing clinical trials for lysosomal storage disorders are underway. This strategy utilizes the ZFN platform and HDR pathway to precisely insert a therapeutic gene into the albumin locus to hijack the strong albumin promoter to drive transgene expression in hepatocytes ${ }^{218-220}$. Other notable therapeutic gene-editing approaches include exon deletion to remove a mutation without disrupting the open reading frame ${ }^{221-223}$, splicing modulation to reframe protein-coding sequences ${ }^{224}$ and allelic exchange to repair recessive compound heterozygous mutations ${ }^{225}$. 
Notably, base editing has emerged as a powerful therapeutic gene-editing approach that directly converts one base pair into another without generating double-stranded DNA breaks. The DNA base editors comprise an RNA-guided, catalytically inactive form of Cas for sequence recognition and a fused effector to achieve base conversion. Refinement of the DNA base editor design has now greatly improved editing efficiency, accuracy and flexibility 226 .

\section{Key challenges}

\section{Large-scale vector manufacturing and cost}

A main barrier for AAV-based gene therapy may be the affordability of the drug product. For example, priced at 1 million euros (US\$1.2 million) per patient at the time of this Review, Glybera still holds the title for the most expensive drug in the world. Luxturna, which was launched in 2017 at US $\$ 425,000$ per eye treatment, has a similarly high price tag. Unfortunately, the price is primarily attributed to the high cost of manufacturing. A great deal of resources and expertise with current production systems is required to generate enough vector to treat a target organ, be it the CNS, the liver or muscle, or to systemically target multiple organs.

Triple transfection of plasmid DNA into adherent eukaryotic cells is common for the production of both research-grade and clinical-grade vectors ${ }^{227,228}$ (BOX 1). Unfortunately, scaling this system is costly, as large-scale production requires increasing the surface area needed to grow packaging cell lines. HEK293 cells have been adapted to grow in suspension in bioreactors to yield over $1 \times 1014$ vector genomes per litre ${ }^{229}$. Despite these advancements, the three-plasmid transfection system remains somewhat inefficient, as not all cells receive optimal ratios of the plasmids required for efficient packaging. Plasmid imbalance may also contribute to the variation in empty-to-full capsid ratios between vector batches. Multiple feasible approaches for generating stable eukaryotic cell lines to circumvent the need for plasmid transfection have been described ${ }^{230}$, but these have yet to be adapted to a suitable clinical production pipeline or are hampered by concerns regarding the use of replicating AdV. Recombinant baculovirus platforms have been widely employed for large-scale production of $\mathrm{rAAV}$ in $\mathrm{Sf} 9$ cells owing to their ease of suspension culturing at high cell densities (BOX 1). Glybera is in fact produced utilizing this method. However, these methods are still sufficient for only a limited number of patients, as the doses necessary to be effective can be very high.

Although treating monogenic disease by rAAV vectors has now become more feasible than ever, the high risk and high cost of developing rAAV-based investigational new drugs (INDs) discourage many investigators from transitioning preclinical studies to clinical trials. Typical FDA-approval for IND trials requires extensive preclinical studies to measure toxicology, safety, dose and bio-distribution ${ }^{227}$. Difficulties with purification of rAAV particles from cellular and viral impurities and removal of AAV empty capsids, lack of standardization (many times owing to differences in vector capsid variant) and inherent batch-to-batch variation of vector potency all impact production costs. 


\section{Vector quality control and assay standardization}

Empty-to-full ratios.-Empty capsids can range from 20\% to over $98 \%$ in vector preparations when produced by standard transient transfection production pipelines ${ }^{231}$. Common semi-quantitative methods of surveying empty or partially empty particles employ electron microscopy, where empty capsids are easily differentiated after negative staining. Absolute quantification of empty versus full capsids used for assaying clinical-grade vectors can be obtained by optical density measurements or sedimentation velocity analytical ultracentrifugation ${ }^{231,232}$. More sophisticated methods employing charge detection mass spectrometry not only are capable of quantifying the distribution of empty-to-full capsids but also can reveal the distribution of partial and/or truncated genomes that are packaged into virions ${ }^{233}$.

Potency assessment.-Robust potency assays for rAAVs should measure the effectiveness of gene transfer. Additionally, these tests should also gauge any biological effects of the transferred gene, which can include toxicity, immunogenicity or transgene clearance. Accurate assessment of rAAV potencies is limited by multiple factors: the animal model it is tested in, the sex of the test subject, the expected effective dose and therapeutic window, the capacity of the vector to evade the immune response, its on-target and off-target infection profile, proper cytosolic trafficking through cellular compartments, mechanisms of capsid escape and transcription of the transgene. In order to provide a robust potency assay for rAAVs, surrogate models, such as mice, serve as the standard in vivo test system for the transduction of the liver ${ }^{234}$. Unfortunately, in vivo models suffer from poor reproducibility. Furthermore, inter-species variation in AAV tropism and transgene expression can result in misrepresented potencies. In vitro proxy assays would be favourable in light of in vivo variability. Thus, potency assays have been developed with fairly high reproducibility ${ }^{235,236}$. Recent reports of ex vivo potency assays for retinal rAAV gene therapy using human retinal explants represent robust potency assays that do not rely on animal models ${ }^{237,238}$.

DNA composition.-Owing to the increasing interest in using rAAVs as clinical vectors, quality control standards for rAAV production are becoming more important than ever. Vector preparation impurities that are carried through from the production workflow can pose substantial risk. Safety profiling assays to screen for adventitious agents are now standard for clinical AAV vectors. The most direct solution to these issues is to employ single-use equipment during production, starting from DNA preparation steps and ending with the validation of DNA purity by high-throughput sequencing approaches ${ }^{239}$.

There has yet to be a standard for assessing the DNA content packaged into AAV particles. For example, in current rAAV production pipelines, nucleic acid contaminants can originate from cellular, viral and plasmid sources. The FDA recommends that the level of residual cell substrate DNA should be below $10 \mathrm{ng}$ per dose and that the median DNA size should be 200 bp or lower. Platforms such as SSV-seq that are based on short-read high-throughput sequencing technologies, can unbiasedly detect host genome contaminants beyond what is feasible for quantitative PCR-based methods ${ }^{240}$. A long-read sequencing method named AAV-GPseq has achieved full single-genome resolution from ITR to ITR and can now determine the distribution of truncated forms ${ }^{196}$, as well as chimeric genomes arising from 
recombination events that result in the generation of heterologous DNAs that can harbour ITRs $^{241}$. The identification and quantification of these species are critical, as these species can theoretically persist once they are transduced into cells after undergoing episome formation via ITR-mediated recombination. These species pose a substantial hazard because they may express proteins or regulatory RNAs. Functionally inert genomes, on the other hand, are counter-productive to efficient gene therapy and may require increased doses to compensate for poor batch potencies. This in turn may cause increased capsid immunological burden and/or possible integration-mediated genotoxicity in patients. Notably, the current platform for AAV-GPseq can also profile single-stranded AAV viral genomes $^{242}$.

Capsid property.-With the development of engineered novel capsids, especially those carrying modifications of VP2 or that are generated from systems that may yield heterogeneity in VP1:VP2:VP3 ratios, methods for the accurate assessment of capsid stability are in high demand. Additionally, the use of mixed serotype (mosaic) capsids that can outperform single serotype capsids ${ }^{243}$ necessitates methods that can quantify the extent of mosaicism. Importantly, what remains under-investigated is whether different production platforms may result in heterogenous capsid characteristics. As alluded to in BOX 1, early versions of baculovirus Sf9 production schemes yielded poor packaging efficiencies for certain serotypes and variable performances in vivo. Classical methods to quantify capsid protein abundance such as silver stain gels are inadequate for assessing capsid heterogeneity. To meet this need, assays based on differential scanning fluorimetry have been developed to detect the differential unfolding of capsids in response to a temperature gradient ${ }^{244-246}$.

\section{Immunological barriers to rAAV gene delivery}

The rAAV protein capsid, its DNA genome and the protein product of the transgene can interact with host immune systems at multiple layers, posing substantial barriers to effective gene delivery and persistent gene expression ${ }^{247,248}$ (FIG. 5). The first barrier concerns the NAbs against the rAAV capsids that are identical or similar to the capsids of wtAAVs. NAbs in the blood circulation are found in a large portion of the human population owing to natural wtAAV infection and can effectively block rAAV gene delivery, especially following intravenous injection ${ }^{249,250}$. The immune-privileged brain can tolerate a somewhat high NAb titre following a direct CNS delivery but is not completely shielded from circulating NAbs ${ }^{251,252}$. Several strategies have been developed to overcome this barrier, such as plasmapheresis ${ }^{253,254}$ and using empty capsids as decoys ${ }^{255}$, but they are not effective in tackling high-titre NAbs. Another approach is to engineer rAAV capsid by eliminating NAbinteracting epitopes ${ }^{101}$. The effectiveness of these strategies under clinical settings remains to be tested. Currently, NAb screening and excluding seropositive subjects from enrolment remain necessary steps in many clinical studies 256,257 .

Following rAAV administration, the vector capsid triggers a robust humoral immune response to generate NAbs, preventing re-administration in most cases ${ }^{258}$. For applications likely requiring repeated dosing, transient $\mathrm{B}$ cell depletion upon the first injection ${ }^{259}$ and induction of immune tolerance by rapamycin ${ }^{260-262}$ may be considered. In addition, the capsid can trigger a cytotoxic T lymphocyte (CTL)-mediated cytotoxicity, which may lead to 
the clearance of transduced cells and therefore loss of transgene expression ${ }^{249,263}$. This phenomenon appears prominent in humans and is not readily modelled in animals. It should be noted that the CTL response mounted against the rAAV capsid is much weaker than those mounted against other viral vectors such as adenoviral vectors. CTL response caused by rAAV administration may compromise therapeutic efficacy over time but generally does not pose a major safety concern ${ }^{118,264}$. Some muscle-targeting clinical studies suggest that regulatory $\mathrm{T}$ (Treg) cells may play a role in restraining the effect of CD8+CTLs ${ }^{265}$. Pharmacological suppression of CD8+ T cells with steroids is effective in managing liver CTL response following systemic rAAV delivery and ensuring long-term transgene expression ${ }^{256,257}$. Inspired by the induction of endogenous Treg cells in muscle-directed rAAV gene therapy and their potential role in limiting CTL response, administering autologous Treg cells as an adjuvant to in vivo gene transfer may provide a powerful approach for modulating rAAV immunity ${ }^{266}$.

The transgene may encode a protein that is foreign to the host, as is the case for gene replacement therapies in patients with a null genotype or gene addition therapies with vectored antibody-like molecules. The transgene product may therefore trigger both B cellmediated and $\mathrm{T}$ cell-mediated adaptive responses to generate transgene product-specific antibodies and CTLs. Circulating antibodies may prevent lasting therapeutic efficacy. Likewise, anti-antibody responses are currently a major barrier for developing AAV vectored antibodies for infectious diseases. The transgene product-specific CTL response was reported in muscle-targeted clinical trials ${ }^{267}$ in liver-directed haemophilia trials ${ }^{256,257}$. Establishing the necessary enrolment criteria could have helped to mitigate such a risk. Importantly, the tolerogenic ability of the liver also impacts rAAV gene transfer ${ }^{268-270}$. The transgene product-specific immune tolerance induced by liver-directed rAAV gene delivery is dose-dependent and likely involves Treg cells. This endogenous immune modulation phenomenon can be harnessed to achieve stable transgene expression and therapeutic efficacy ${ }^{271},{ }^{272}$.

In addition to eliciting adaptive responses, the rAAV capsid and vector genome are also sensed shortly after delivery by the innate immunity through Toll-like receptor 2 (TLR2) and TLR9, respectively. This response leads to the production of pro-inflammatory cytokines and promotes the adaptive response ${ }^{273}$. Self-complementary rAAV genomes ${ }^{274}$ or vector genomes with high content ${ }^{275}$ were shown to further enhance the immune response. Therefore, preventing TLR signalling by depleting CpG dinucleotides in the rAAV genome has the potential to enhance rAAV-mediated gene expression ${ }^{275}$. Another promising strategy is to incorporate a TLR9-inhibitory DNA sequence, such as multiple copies of TTAGGG derived from human telomeres, into the rAAV genome to evade innate immune surveillance 276 . This approach was reported to reduce the immune responses associated with rAAV delivery in mice.

\section{Conclusions, perspectives and future directions}

In conclusion, we have provided an AAV-centric view of current trends, challenges and milestones in the field of gene therapy. This Review has covered only a small part of an ever-expanding field. The range of technology platforms that constitute gene therapy is quite 
diverse, and substantial innovations have been made in the areas of cell therapy, gene editing, nanoparticle engineering and other gene delivery platforms. As technology continues to advance, the gene therapy field may become so diverse and accelerate so quickly that some of these technologies may fall out of favour before reaching the clinic. This is certainly possible for some rAAV-based strategies. Nevertheless, the current exponential growth of clinical trials using AAV vectors suggests that we are only at the beginnings of what is achievable for an inconsequential virus that has now become a programmable vector to improve human health.

Although the study of AAV is necessarily a discipline of virology, to adapt AAV into a gene therapy vector required a multidisciplinary approach. It has become abundantly clear that such advances would not have been possible were it not for contributions from the fields of molecular biology, bioinformatics, epidemiology, structural biology, immunology, genomics and all other disciplines that fall under the umbrella of biomedical research. Our hope is that as the AAV field continues to expand, a multidisciplinary approach to gene therapy drug development will continue to be fostered. In many ways, this goal is self-fulfilling, as gene therapy represents one of the final frontiers for curing human ailments. The human genome projects have achieved near complete annotation of the genome. Additionally, genome-wide association study projects and big data studies that explore the epigenome have provided the blueprints for linking genetic differences with disease. These achievements have put us in the middle of the very exciting genomics and gene therapeutics age. Harnessing the genetic code to develop innovative medicines will require contributions from all areas of scientific expertise to fully tap into the promise of rAAV gene therapy and to overcome current challenges.

\section{Acknowledgements}

The authors thank H. Ma for figure concepts and illustration and L. Ren for compiling data for the table of adenoassociated virus (AAV) gene therapy clinical trials. The authors thank all members of the Gao laboratory and their numerous colleagues for productive collaborations and stimulating discussions on AAV and gene therapy. They also thank The American Society of Gene and Cell Therapy and all members of the gene therapy field for their invaluable contributions. The authors apologize for not being able to be more comprehensive in reviewing all the work of their colleagues owing to space limitations. Research in the Gao laboratory is supported by grants from the National Institutes of Health (NIH), the CHDI Foundation, the Grace Science Foundation and the authors' industry partners.

\section{References}

1. Atchison RW, Casto BC \& Hammon WM Adenovirus-associated defective virus particles. Science 149, 754-756 (1965). [PubMed: 14325163] This report is among the first to identify by electron microscopy the presence of AAV as a defective virus in simian AdV preparations.

2. Hoggan MD, Blacklow NR \& Rowe WP Studies of small DNA viruses found in various adenovirus preparations: physical, biological, and immunological characteristics. Proc. Natl Acad. Sci. USA 55, 1467-1474 (1966). [PubMed: 5227666]

3. Blacklow NR, Hoggan MD \& Rowe WP Isolation of adenovirus-associated viruses from man. Proc. Natl Acad. Sci. USA 58, 1410-1415 (1967). [PubMed: 4295829]

4. Carter BJ Adeno-associated virus and the development of adeno-associated virus vectors: a historical perspective. Mol. Ther 10, 981-989 (2004). [PubMed: 15564130]

5. Berns KI My life with adeno-associated virus: a long time spent studying a short genome. DNA Cell Biol. 32, 342-347 (2013). [PubMed: 23781880] 
6. Hastie E \& Samulski RJ Adeno-associated virus at 50: a golden anniversary of discovery, research, and gene therapy success-a personal perspective. Hum. Gene Ther 26, 257-265 (2015). [PubMed: 25807962]

7. Crawford LV, Follett EA, Burdon MG \& McGeoch DJ The DNA of a minute virus of mice. J. Gen. Virol 4, 37-46 (1969). [PubMed: 4975639]

8. Rose JA, Berns KI, Hoggan MD \& Koczot FJ Evidence for a single-stranded adenovirus-associated virus genome: formation of a DNA density hybrid on release of viral DNA. Proc. Natl Acad. Sci. USA 64, 863-869 (1969). [PubMed: 5264145]

9. Carter BJ, Khoury G \& Denhardt DT Physical map and strand polarity of specific fragments of adenovirus-associated virus DNA produced by endonuclease R-EcoRI. J. Virol 16, 559-568 (1975). [PubMed: 1159894]

10. Lusby E, Fife KH \& Berns KI Nucleotide sequence of the inverted terminal repetition in adenoassociated virus DNA. J. Virol 34, 402-409 (1980). [PubMed: 6246271]

11. Carter BJ, Khoury G \& Rose JA Adenovirus-associated virus multiplication. IX. Extent of transcription of the viral genome in vivo. J. Virol 10, 1118-1125 (1972). [PubMed: 4345491]

12. Hauswirth WW \& Berns KI Origin and termination of adeno-associated virus DNA replication. Virology 78, 488-499 (1977). [PubMed: 867815]

13. Marcus CJ, Laughlin CA \& Carter BJ Adeno-associated virus RNA transcription in vivo. Eur. J. Biochem 121, 147-154 (1981). [PubMed: 6173214]

14. Berns KI, Pinkerton TC, Thomas GF \& Hoggan MD Detection of adeno-associated virus (AAV)specific nucleotide sequences in DNA isolated from latently infected Detroit 6 cells. Virology 68, 556-560 (1975). [PubMed: 1198930]

15. Cheung AK, Hoggan MD, Hauswirth WW \& Berns KI Integration of the adeno-associated virus genome into cellular DNA in latently infected human Detroit 6 cells. J. Virol 33, 739-748 (1980). [PubMed: 6251245]

16. Kotin RM \& Berns KI Organization of adeno-associated virus DNA in latently infected Detroit 6 cells. Virology 170, 460-467 (1989). [PubMed: 2543124]

17. Kotin RM et al. Site-specific integration by adeno-associated virus. Proc. Natl Acad. Sci. USA 87, 2211-2215 (1990). [PubMed: 2156265]

18. Kotin RM, Menninger JC, Ward DC \& Berns KI Mapping and direct visualization of a regionspecific viral DNA integration site on chromosome 19q13-qter. Genomics 10, 831-834 (1991). [PubMed: 1653762] References 17 and 18 are the first reports to describe latent AAV genomes integrating into a specific region of human chromosome 19, which was later characterized and named AAVS1.

19. Linden RM, Ward P, Giraud C, Winocour E \& Berns KI Site-specific integration by adenoassociated virus. Proc. Natl Acad. Sci. USA 93, 11288-11294 (1996). [PubMed: 8876128]

20. Myers MW \& Carter BJ Assembly of adeno-associated virus. Virology 102, 71-82 (1980). [PubMed: 6245509]

21. Samulski RJ, Berns KI, Tan M \& Muzyczka N Cloning of adeno-associated virus into pBR322: rescue of intact virus from the recombinant plasmid in human cells. Proc. Natl Acad. Sci. USA 79, 2077-2081 (1982). [PubMed: 6281795]

22. Laughlin CA, Tratschin JD, Coon H \& Carter BJ Cloning of infectious adeno-associated virus genomes in bacterial plasmids. Gene 23, 65-73 (1983). [PubMed: 6352411]

23. Srivastava A, Lusby EW \& Berns KI Nucleotide sequence and organization of the adenoassociated virus 2 genome. J. Virol 45, 555-564 (1983). [PubMed: 6300419]

24. Yla-Herttuala S Endgame: glybera finally recommended for approval as the first gene therapy drug in the European union. Mol. Ther 20, 1831-1832 (2012). [PubMed: 23023051]

25. Colella P, Ronzitti G \& Mingozzi F Emerging issues in AAV-mediated in vivo gene therapy. Mol. Ther. Methods Clin. Dev 8, 87-104 (2018). [PubMed: 29326962]

26. Wang D \& Gao G State-of-the-art human gene therapy: part I. Gene delivery technologies. Discov. Med 18, 67-77 (2014). [PubMed: 25091489]

27. Vannucci L, Lai M, Chiuppesi F, Ceccherini-Nelli L \& Pistello M Viral vectors: a look back and ahead on gene transfer technology. New Microbiol. 36, 1-22 (2013). [PubMed: 23435812] 
28. Yin H et al. Non-viral vectors for gene-based therapy. Nat. Rev. Genet 15, 541-555 (2014). [PubMed: 25022906]

29. Muzyczka N \& Berns K in Fields Virology Vol. 2 (eds Knipe D et al.) 2327-2359 (Lippincott, Williams and Wilkins, 2001).

30. Sonntag F, Schmidt K \& Kleinschmidt JA A viral assembly factor promotes AAV2 capsid formation in the nucleolus. Proc. Natl Acad. Sci. USA 107, 10220-10225 (2010). [PubMed: 20479244]

31. Sonntag F et al. The assembly-activating protein promotes capsid assembly of different adenoassociated virus serotypes. J. Virol 85, 12686-12697 (2011). [PubMed: 21917944]

32. Samulski RJ et al. Targeted integration of adeno-associated virus (AAV) into human chromosome 19. EMBO J. 10, 3941-3950 (1991). [PubMed: 1657596]

33. Philpott NJ, Gomos J, Berns KI \& Falck-Pedersen E A p5 integration efficiency element mediates Rep-dependent integration into AAVS1 at chromosome 19. Proc. Natl Acad. Sci. USA 99, 1238112385 (2002). [PubMed: 12221283]

34. Linden RM, Winocour E \& Berns KI The recombination signals for adeno-associated virus sitespecific integration. Proc. Natl Acad. Sci. USA 93, 7966-7972 (1996). [PubMed: 8755586]

35. Dong JY, Fan PD \& Frizzell RA Quantitative analysis of the packaging capacity of recombinant adeno-associated virus. Hum. Gene Ther 7, 2101-2112 (1996). [PubMed: 8934224]

36. Denard J et al. AAV-8 and AAV-9 vectors cooperate with serum proteins differently than AAV-1 and AAV-6. Mol. Ther. Methods Clin. Dev 10, 291-302 (2018). [PubMed: 30155509]

37. Huang LY, Halder S \& Agbandje-McKenna M Parvovirus glycan interactions. Curr. Opin. Virol 7 , 108-118 (2014). [PubMed: 25047752]

38. Agbandje-McKenna M \& Kleinschmidt J AAV capsid structure and cell interactions. Methods Mol. Biol 807, 47-92 (2011). [PubMed: 22034026] This book chapter serves as an excellent general review on AAV capsid biology, function and structure and provides detailed descriptions for AAV purification and characterization studies.

39. Nonnenmacher $\mathrm{M} \&$ Weber T Intracellular transport of recombinant adeno-associated virus vectors. Gene Ther. 19, 649-658 (2012). [PubMed: 22357511]

40. Pillay S et al. An essential receptor for adeno-associated virus infection. Nature 530, 108-112 (2016). [PubMed: 26814968]

41. Pillay S et al. Adeno-associated virus (AAV) serotypes have distinctive interactions with domains of the cellular AAV receptor. J. Virol 91, e00391-17 (2017). [PubMed: 28679762]

42. Summerford C, Johnson JS \& Samulski RJ AAVR: a multi-serotype receptor for AAV. Mol. Ther 24, 663-666 (2016). [PubMed: 27081719]

43. Drouin LM \& Agbandje-McKenna M Adeno-associated virus structural biology as a tool in vector development. Future Virol. 8, 1183-1199 (2013). [PubMed: 24533032]

44. Duan D et al. Dynamin is required for recombinant adeno-associated virus type 2 infection. J. Virol 73, 10371-10376 (1999). [PubMed: 10559355]

45. Bartlett JS, Wilcher R \& Samulski RJ Infectious entry pathway of adeno-associated virus and adeno-associated virus vectors. J. Virol 74, 2777-2785 (2000). [PubMed: 10684294]

46. Nonnenmacher $\mathrm{M} \&$ Weber $\mathrm{T}$ Adeno-associated virus 2 infection requires endocytosis through the CLIC/GEEC pathway. Cell Host Microbe 10, 563-576 (2011). [PubMed: 22177561]

47. Sonntag F, Bleker S, Leuchs B, Fischer R \& Kleinschmidt JA Adeno-associated virus type 2 capsids with externalized VP1/VP2 trafficking domains are generated prior to passage through the cytoplasm and are maintained until uncoating occurs in the nucleus. J. Virol 80, 11040-11054 (2006). [PubMed: 16956943]

48. Xiao PJ \& Samulski RJ Cytoplasmic trafficking, endosomal escape, and perinuclear accumulation of adeno-associated virus type 2 particles are facilitated by microtubule network. J. Virol 86, 10462-10473 (2012). [PubMed: 22811523]

49. Xiao W et al. Adenovirus-facilitated nuclear translocation of adeno-associated virus type 2. J. Virol 76, 11505-11517 (2002). [PubMed: 12388712]

50. Nicolson SC \& Samulski RJ Recombinant adeno-associated virus utilizes host cell nuclear import machinery to enter the nucleus. J. Virol 88, 4132-4144 (2014). [PubMed: 24478436] 
51. Kelich JM et al. Super-resolution imaging of nuclear import of adeno-associated virus in live cells. Mol. Ther. Methods Clin. Dev 2, 15047 (2015). [PubMed: 26665132]

52. Fisher KJ et al. Transduction with recombinant adeno-associated virus for gene therapy is limited by leading-strand synthesis. J. Virol 70, 520-532 (1996). [PubMed: 8523565]

53. Ferrari FK, Samulski T, Shenk T \& Samulski RJ Second-strand synthesis is a rate-limiting step for efficient transduction by recombinant adeno-associated virus vectors. J. Virol 70, 3227-3234 (1996). [PubMed: 8627803]

54. Zhou X et al. Adeno-associated virus of a single-polarity DNA genome is capable of transduction in vivo. Mol. Ther 16, 494-499 (2008). [PubMed: 18180769]

55. Zhong L et al. Single-polarity recombinant adeno-associated virus 2 vector-mediated transgene expression in vitro and in vivo: mechanism of transduction. Mol. Ther 16, 290-295 (2008). [PubMed: 18087261]

56. Nakai H, Storm TA \& Kay MA Recruitment of single-stranded recombinant adeno-associated virus vector genomes and intermolecular recombination are responsible for stable transduction of liver in vivo. J. Virol 74, 9451-9463 (2000). [PubMed: 11000214]

57. McCarty DM et al. Adeno-associated virus terminal repeat (TR) mutant generates selfcomplementary vectors to overcome the rate-limiting step to transduction in vivo. Gene Ther. 10, 2112-2118 (2003). [PubMed: 14625565]

58. Wang $\mathrm{Z}$ et al. Rapid and highly efficient transduction by double-stranded adeno-associated virus vectors in vitro and in vivo. Gene Ther. 10, 2105-2111 (2003). [PubMed: 14625564]

59. Duan D et al. Circular intermediates of recombinant adeno-associated virus have defined structural characteristics responsible for long-term episomal persistence in muscle tissue. J. Virol 72, 85688577 (1998). [PubMed: 9765395] This study formally demonstrates that rAAVs show stability and long-term persistence in tissues as circularized monomers and concatemers through recombination to form episomal genomes.

60. Duan D, Yan Z, Yue Y \& Engelhardt JF Structural analysis of adeno-associated virus transduction circular intermediates. Virology 261, 8-14 (1999). [PubMed: 10484751]

61. Drouin LM et al. Cryo-electron microscopy reconstruction and stability studies of the wild type and the R432A variant of adeno-associated virus type 2 reveal that capsid structural stability is a major factor in genome packaging. J. Virol 90, 8542-8551 (2016). [PubMed: 27440903]

62. Gurda BL et al. Capsid antibodies to different adeno-associated virus serotypes bind common regions. J. Virol 87, 9111-9124 (2013). [PubMed: 23760240]

63. Gao G et al. Clades of Adeno-associated viruses are widely disseminated in human tissues. J. Virol 78, 6381-6388 (2004). [PubMed: 15163731] This study explores the diversity of AAV proviral sequences derived from human and NHP tissues and establishes the classification for the six AAV clades (A-F).

64. Gao GP et al. Novel adeno-associated viruses from rhesus monkeys as vectors for human gene therapy. Proc. Natl Acad. Sci. USA 99, 11854-11859 (2002). [PubMed: 12192090] This study identifies AAV7 and AAV8 in rhesus macaques by molecular cloning methods and establishes AAVs derived from NHPs as promising capsids for vectorization and therapeutic application.

65. Gao $\mathrm{G}$ et al. Adeno-associated viruses undergo substantial evolution in primates during natural infections. Proc. Natl Acad. Sci. USA 100, 6081-6086 (2003). [PubMed: 12716974]

66. Schnepp BC, Jensen RL, Chen CL, Johnson PR \& Clark KR Characterization of adeno-associated virus genomes isolated from human tissues. J. Virol 79, 14793-14803 (2005). [PubMed: 16282479]

67. Schnepp BC, Jensen RL, Clark KR \& Johnson PR Infectious molecular clones of adeno-associated virus isolated directly from human tissues. J. Virol 83, 1456-1464 (2009). [PubMed: 19019948]

68. Smith LJ et al. Gene transfer properties and structural modeling of human stem cell-derived AAV. Mol. Ther 22, 1625-1634 (2014). [PubMed: 24925207]

69. Smith LJ et al. Stem cell-derived clade F AAVs mediate high-efficiency homologous recombination-based genome editing. Proc. Natl Acad. Sci. USA 115, E7379-E7388 (2018). [PubMed: 30018062] This report describes the isolation of haematopoietic stem cell-derived AAVs that have the capacity to mediate gene editing via homologous recombination of the vector genome as a template without the need for exogenous nucleases. 
70. Calcedo R et al. Adeno-associated virus antibody profiles in newborns, children, and adolescents. Clin. Vaccine Immunol 18, 1586-1588 (2011). [PubMed: 21775517]

71. Huser D et al. High prevalence of infectious adeno-associated virus (AAV) in human peripheral blood mononuclear cells indicative of T lymphocytes as sites of AAV persistence. J. Virol 91, e02137-16 (2017). [PubMed: 27928011]

72. Chen CL et al. Molecular characterization of adeno-associated viruses infecting children. J. Virol 79, 14781-14792 (2005). [PubMed: 16282478]

73. Calcedo R, Vandenberghe LH, Gao G, Lin J \& Wilson JM Worldwide epidemiology of neutralizing antibodies to adeno-associated viruses. J. Infect. Dis 199, 381-390 (2009). [PubMed: 19133809]

74. Halbert CL et al. Prevalence of neutralizing antibodies against adeno-associated virus (AAV) types 2, 5, and 6 in cystic fibrosis and normal populations: Implications for gene therapy using AAV vectors. Hum. Gene Ther 17, 440-447 (2006). [PubMed: 16610931]

75. Boutin $\mathrm{S}$ et al. Prevalence of serum IgG and neutralizing factors against adeno-associated virus (AAV) types 1, 2, 5, 6, 8, and 9 in the healthy population: implications for gene therapy using AAV vectors. Hum. Gene Ther 21, 704-712 (2010). [PubMed: 20095819]

76. Yates VJ, el-Mishad AM, McCormick KJ \& Trentin JJ Isolation and characterization of an Avian adenovirus-associated virus. Infect. Immun 7, 973-980 (1973). [PubMed: 4351971]

77. Lochrie MA et al. Adeno-associated virus (AAV) capsid genes isolated from rat and mouse liver genomic DNA define two new AAV species distantly related to AAV-5. Virology 353, 68-82 (2006). [PubMed: 16806384]

78. Arbetman AE et al. Novel caprine adeno-associated virus (AAV) capsid (AAV-Go.1) is closely related to the primate AAV-5 and has unique tropism and neutralization properties. J. Virol 79, 15238-15245 (2005). [PubMed: 16306595]

79. Clarke JK, McFerran JB, McKillop ER \& Curran WL Isolation of an adeno associated virus from sheep. Arch. Virol 60, 171-176 (1979). [PubMed: 226038]

80. Bello A et al. Isolation and evaluation of novel adeno-associated virus sequences from porcine tissues. Gene Ther. 16, 1320-1328 (2009). [PubMed: 19626054]

81. Li Y et al. Host range, prevalence, and genetic diversity of adenoviruses in bats. J. Virol 84, 3889 3897 (2010). [PubMed: 20089640]

82. Farkas SL et al. A parvovirus isolated from royal python (Python regius) is a member of the genus Dependovirus. J. Gen. Virol 85, 555-561 (2004). [PubMed: 14993638]

83. Myrup AC, Mohanty SB \& Hetrick FM Isolation and characterization of adeno-associated viruses from bovine adenovirus types 1 and 2. Am. J. Vet. Res 37, 907-910 (1976). [PubMed: 986122]

84. Bello A et al. Novel adeno-associated viruses derived from pig tissues transduce most major organs in mice. Sci. Rep 4, 6644 (2014). [PubMed: 25335510]

85. Eid J et al. Real-time DNA sequencing from single polymerase molecules. Science 323, 133-138 (2009). [PubMed: 19023044]

86. $\mathrm{Xu} \mathrm{G}$ et al. High-throughput sequencing of AAV proviral libraries from the human population reveals novel variants with unprecedented intra- and inter-tissue diversity. Mol. Ther 24, S4 (2016).

87. Chen YH, Chang M \& Davidson BL Molecular signatures of disease brain endothelia provide new sites for CNS-directed enzyme therapy. Nat. Med 15, 1215-1218 (2009). [PubMed: 19749771]

88. Girod A et al. Genetic capsid modifications allow efficient re-targeting of adeno-associated virus type 2. Nat. Med 5, 1052-1056 (1999). [PubMed: 10470084]

89. Warrington KH Jr et al. Adeno-associated virus type 2 VP2 capsid protein is nonessential and can tolerate large peptide insertions at its $\mathrm{N}$ terminus. J. Virol 78, 6595-6609 (2004). [PubMed: 15163751]

90. Yang Q et al. Development of novel cell surface CD34-targeted recombinant adenoassociated virus vectors for gene therapy. Hum. Gene Ther 9, 1929-1937 (1998). [PubMed: 9741431]

91. Munch RC et al. Off-target-free gene delivery by affinity-purified receptor-targeted viral vectors. Nat. Commun 6, 6246 (2015). [PubMed: 25665714]

92. Asokan A et al. Reengineering a receptor footprint of adeno-associated virus enables selective and systemic gene transfer to muscle. Nat. Biotechnol 28, 79-82 (2010). [PubMed: 20037580] 
93. Bowles DE et al. Phase 1 gene therapy for Duchenne muscular dystrophy using a translational optimized AAV vector. Mol. Ther 20, 443-455 (2012). [PubMed: 22068425]

94. Zhang C et al. Development of next generation adeno-associated viral vectors capable of selective tropism and efficient gene delivery. Biomaterials 80, 134-145 (2016). [PubMed: 26708090]

95. Kelemen RE et al. A precise chemical strategy to alter the receptor specificity of the adenoassociated virus. Angew. Chem. Int. Ed 55, 10645-10649 (2016).

96. Yao $\mathrm{T}$ et al. Site-specific pegylated adeno-associated viruses with increased serum stability and reduced immunogenicity. Molecules 22, E1155 (2017). [PubMed: 28696391]

97. Katrekar D, Moreno AM, Chen G, Worlikar A \& Mali P Oligonucleotide conjugated multifunctional adeno-associated viruses. Sci. Rep 8, 3589 (2018). [PubMed: 29483550]

98. Zhong L et al. Next generation of adeno-associated virus 2 vectors: point mutations in tyrosines lead to high-efficiency transduction at lower doses. Proc. Natl Acad. Sci. USA 105, 7827-7832 (2008). [PubMed: 18511559]

99. Tordo J et al. A novel adeno-associated virus capsid with enhanced neurotropism corrects a lysosomal transmembrane enzyme deficiency. Brain 141, 2014-2031 (2018). [PubMed: 29788236]

100. Wang D et al. A rationally engineered capsid variant of AAV9 for systemic CNS-directed and peripheral tissue-detargeted gene delivery in neonates. Mol. Ther. Methods Clin. Dev 9, 234-246 (2018). [PubMed: 29766031]

101. Tse LV et al. Structure-guided evolution of antigenically distinct adeno-associated virus variants for immune evasion. Proc. Natl Acad. Sci. USA 114, E4812-E4821 (2017). [PubMed: 28559317]

102. Paulk NK et al. Bioengineered AAV capsids with combined high human liver transduction in vivo and unique humoral seroreactivity. Mol. Ther 26, 289-303 (2018). [PubMed: 29055620]

103. Maheshri N, Koerber JT, Kaspar BK \& Schaffer DV Directed evolution of adeno-associated virus yields enhanced gene delivery vectors. Nat. Biotechnol 24, 198-204 (2006). [PubMed: 16429148] This study demonstrates the feasibility of directed evolution of AAV vectors for desired clinical features.

104. Koerber JT, Jang JH \& Schaffer DV DNA shuffling of adeno-associated virus yields functionally diverse viral progeny. Mol. Ther 16, 1703-1709 (2008). [PubMed: 18728640]

105. Kotterman MA \& Schaffer DV Engineering adeno-associated viruses for clinical gene therapy. Nat. Rev. Genet 15, 445-451 (2014). [PubMed: 24840552]

106. Choudhury SR et al. In vivo selection yields AAV-B1 capsid for central nervous system and muscle gene therapy. Mol. Ther 24, 1247-1257 (2016). [PubMed: 27117222]

107. Li W et al. Generation of novel AAV variants by directed evolution for improved CFTR delivery to human ciliated airway epithelium. Mol. Ther 17, 2067-2077 (2009). [PubMed: 19603002]

108. Yang L et al. A myocardium tropic adeno-associated virus (AAV) evolved by DNA shuffling and in vivo selection. Proc. Natl Acad. Sci. USA 106, 3946-3951 (2009). [PubMed: 19234115]

109. Sallach J et al. Tropism-modified AAV vectors overcome barriers to successful cutaneous therapy. Mol. Ther 22, 929-939 (2014). [PubMed: 24468915]

110. Deverman BE et al. Cre-dependent selection yields AAV variants for widespread gene transfer to the adult brain. Nat. Biotechnol 34, 204-209 (2016). [PubMed: 26829320] This paper describes the development of a Cre recombination-based method to screen AAV capsid libraries in mice and through this approach identifies AAV-PHP.B.

111. Lisowski $\mathrm{L}$ et al. Selection and evaluation of clinically relevant AAV variants in a xenograft liver model. Nature 506, 382-386 (2014). [PubMed: 24390344] This study utilizes a human xenograft mouse model to identify an AAV capsid that has tropism to human hepatocytes, aiming to overcome the limitation of using non-human evolution systems.

112. Grimm D et al. In vitro and in vivo gene therapy vector evolution via multispecies interbreeding and retargeting of adeno-associated viruses. J. Virol 82, 5887-5911 (2008). [PubMed: 18400866]

113. Gray SJ et al. Directed evolution of a novel adeno-associated virus (AAV) vector that crosses the seizure-compromised blood-brain barrier (BBB). Mol. Ther 18, 570-578 (2010). [PubMed: 20040913] 
114. Wooley DP et al. A directed evolution approach to select for novel Adeno-associated virus capsids on an HIV-1 producer T cell line. J. Virol. Methods 250, 47-54 (2017). [PubMed: 28918073]

115. Chan KY et al. Engineered AAVs for efficient noninvasive gene delivery to the central and peripheral nervous systems. Nat. Neurosci 20, 1172-1179 (2017). [PubMed: 28671695]

116. Matsuzaki $Y$ et al. Intravenous administration of the adeno-associated virus-PHP. B capsid fails to upregulate transduction efficiency in the marmoset brain. Neurosci. Lett 665, 182-188 (2017). [PubMed: 29175632]

117. Hordeaux $\mathrm{J}$ et al. The neurotropic properties of AAV-PHP. B are limited to C57BL/6J mice. Mol. Ther 26, 664-668 (2018). [PubMed: 29428298]

118. Hinderer $\mathrm{C}$ et al. Severe toxicity in nonhuman primates and piglets following high-dose intravenous administration of an adeno-associated virus vector expressing human SMN. Hum. Gene Ther 29, 285-298 (2018). [PubMed: 29378426]

119. Marsic D et al. Vector design Tour de Force: integrating combinatorial and rational approaches to derive novel adeno-associated virus variants. Mol. Ther 22, 1900-1909 (2014). [PubMed: 25048217]

120. Zinn E et al. In silico reconstruction of the viral evolutionary lineage yields a potent gene therapy vector. Cell Rep. 12, 1056-1068 (2015). [PubMed: 26235624] This manuscript demonstrates the power of in silico AAV capsid design and the development of non-natural capsids termed ancestral AAVs with potent transduction characteristics.

121. Landegger LD et al. A synthetic AAV vector enables safe and efficient gene transfer to the mammalian inner ear. Nat. Biotechnol 35, 280-284 (2017). [PubMed: 28165475]

122. Smith RH et al. Germline viral "fossils" guide in silico reconstruction of a mid-Cenozoic era marsupial adeno-associated virus. Sci. Rep 6, 28965 (2016). [PubMed: 27377618]

123. Lu J, Zhang F \& Kay MA A mini-intronic plasmid (MIP): a novel robust transgene expression vector in vivo and in vitro. Mol. Ther 21, 954-963 (2013). [PubMed: 23459514]

124. Lu J et al. A 5' noncoding exon containing engineered intron enhances transgene expression from recombinant AAV vectors in vivo. Hum. Gene Ther 28, 125-134 (2017). [PubMed: 27903072]

125. Donello JE, Loeb JE \& Hope TJ Woodchuck hepatitis virus contains a tripartite posttranscriptional regulatory element. J. Virol 72, 5085-5092 (1998). [PubMed: 9573279]

126. Loeb JE, Cordier WS, Harris ME, Weitzman MD \& Hope TJ Enhanced expression of transgenes from adeno-associated virus vectors with the woodchuck hepatitis virus posttranscriptional regulatory element: implications for gene therapy. Hum. Gene Ther 10, 2295-2305 (1999). [PubMed: 10515449]

127. Kingsman SM, Mitrophanous K \& Olsen JC Potential oncogene activity of the woodchuck hepatitis post-transcriptional regulatory element (WPRE). Gene Ther. 12, 3-4 (2005). [PubMed: 15510172]

128. Patel M \& Olsen JC Optimizing the woodchuck hepatitis virus post-transcriptional regulatory element (WPRE) for safety and function in lentiviral vectors. Mol. Ther 11, S322 (2005).

129. Wang L, Wang H, Bell P, McMenamin D \& Wilson JM Hepatic gene transfer in neonatal mice by adeno-associated virus serotype 8 vector. Hum. Gene Ther 23, 533-539 (2012). [PubMed: 22098408]

130. Gessler DJ et al. Redirecting N-acetylaspartate metabolism in the central nervous system normalizes myelination and rescues Canavan disease. JCI Insight 2, e90807 (2017). [PubMed: 28194442]

131. Nathwani AC et al. Self-complementary adeno-associated virus vectors containing a novel liverspecific human factor IX expression cassette enable highly efficient transduction of murine and nonhuman primate liver. Blood 107, 2653-2661 (2006). [PubMed: 16322469]

132. Ronzitti $\mathrm{G}$ et al. A translationally optimized AAV-UGT1A1 vector drives safe and long-lasting correction of Crigler-Najjar syndrome. Mol. Ther. Methods Clin. Dev 3, 16049 (2016). [PubMed: 27722180]

133. Grimm D, Pandey K \& Kay MA Adeno-associated virus vectors for short hairpin RNA expression. Methods Enzymol. 392, 381-405 (2005). [PubMed: 15644194] 
134. Garg SK et al. Systemic delivery of MeCP2 rescues behavioral and cellular deficits in female mouse models of Rett syndrome. J. Neurosci 33, 13612-13620 (2013). [PubMed: 23966684]

135. Gadalla KKE et al. Development of a novel AAV gene therapy cassette with improved safety features and efficacy in a mouse model of Rett syndrome. Mol. Ther. Methods Clin. Dev 5, 180190 (2017). [PubMed: 28497075]

136. Golebiowski D et al. Direct intracranial injection of AAVrh8 encoding monkey beta-Nacetylhexosaminidase causes neurotoxicity in the primate brain. Hum. Gene Ther 28, 510-522 (2017). [PubMed: 28132521]

137. Grimm D et al. Fatality in mice due to oversaturation of cellular microRNA/short hairpin RNA pathways. Nature 441, 537-541 (2006). [PubMed: 16724069]

138. McBride JL et al. Artificial mi-RNAs mitigate shRNA-mediated toxicity in the brain: implications for the therapeutic development of RNAi. Proc. Natl Acad. Sci. USA 105, 5868-5873 (2008). [PubMed: 18398004]

139. Boudreau RL, Martins I \& Davidson BL Artificial microRNAs as siRNA shuttles: improved safety as compared to shRNAs in vitro and in vivo. Mol. Ther 17, 169-175 (2009). [PubMed: 19002161]

140. Stoica L et al. AAV delivered artificial microRNA extends survival and delays paralysis in an Amyotrophic Lateral Sclerosis mouse model. Ann. Neurol 79, 687-700 (2016). [PubMed: 26891182]

141. Pfister EL et al. Artificial mi-RNAs reduce human mutant huntingtin throughout the striatum in a transgenic sheep model of Huntington's disease. Hum. Gene Ther 29, 663-673 (2018). [PubMed: 29207890]

142. Pfister EL et al. Safe and efficient silencing with a Pol II, but not a Pol III, promoter expressing an artificial miRNA targeting human huntingtin. Mol. Ther. Nucleic Acids 7, 324-334 (2017). [PubMed: 28624208]

143. Gray SJ et al. Optimizing promoters for recombinant adeno-associated virus-mediated gene expression in the peripheral and central nervous system using self-complementary vectors. Hum. Gene Ther 22, 1143-1153 (2011). [PubMed: 21476867]

144. Brown BD, Venneri MA, Zingale A, Sergi Sergi L \& Naldini L Endogenous microRNA regulation suppresses transgene expression in hematopoietic lineages and enables stable gene transfer. Nat. Med 12, 585-591 (2006). [PubMed: 16633348]

145. Xie J et al. MicroRNA-regulated, systemically delivered rAAV9: a step closer to CNS-restricted transgene expression. Mol. Ther 19, 526-535 (2011). [PubMed: 21179009]

146. Qiao C et al. Liver-specific microRNA-122 target sequences incorporated in AAV vectors efficiently inhibits transgene expression in the liver. Gene Ther. 18, 403-410 (2011). [PubMed: 21150938]

147. Geisler A et al. microRNA122-regulated transgene expression increases specificity of cardiac gene transfer upon intravenous delivery of AAV9 vectors. Gene Ther. 18, 199-209 (2011). [PubMed: 21048795]

148. Majowicz A et al. Mir-142-3p target sequences reduce transgene-directed immunogenicity following intramuscular adeno-associated virus 1 vector-mediated gene delivery. J. Gene Med 15, 219-232 (2013). [PubMed: 23658149]

149. Boisgerault $\mathrm{F}$ et al. Prolonged gene expression in muscle is achieved without active immune tolerance using microrRNA 142.3p-regulated rAAV gene transfer. Hum. Gene Ther 24, 393-405 (2013). [PubMed: 23427817]

150. Duan D Systemic AAV micro-dystrophin gene therapy for Duchenne muscular dystrophy. Mol. Ther 26, 2337-2356 (2018). [PubMed: 30093306] This review comprehensively describes the history, current status and future goals for AAV micro-dystrophin gene therapy.

151. England SB et al. Very mild muscular dystrophy associated with the deletion of $46 \%$ of dystrophin. Nature 343, 180-182 (1990). [PubMed: 2404210]

152. Sondergaard PC et al. AAV. Dysferlin overlap vectors restore function in dysferlinopathy animal models. Ann. Clin. Transl Neurol 2, 256-270 (2015). [PubMed: 25815352] 
153. Zhang W, Li L, Su Q, Gao G \& Khanna H Gene therapy using a miniCEP290 fragment delays photoreceptor degeneration in a mouse model of leber congenital amaurosis. Hum. Gene Ther 29, 42-50 (2018). [PubMed: 28679290]

154. Duan D, Yue Y, Yan Z \& Engelhardt JF A new dual-vector approach to enhance recombinant adeno-associated virus-mediated gene expression through intermolecular cis activation. Nat. Med 6, 595-598 (2000). [PubMed: 10802719]

155. Sun L, Li J \& Xiao X Overcoming adeno-associated virus vector size limitation through viral DNA heterodimerization. Nat. Med 6, 599-602 (2000). [PubMed: 10802720]

156. Nakai H, Storm TA \& Kay MA Increasing the size of rAAV-mediated expression cassettes in vivo by intermolecular joining of two complementary vectors. Nat. Biotechnol 18, 527-532 (2000). [PubMed: 10802620]

157. McClements ME \& MacLaren RE Adeno-associated virus (AAV) dual vector strategies for gene therapy encoding large transgenes. Yale J. Biol. Med 90, 611-623 (2017). [PubMed: 29259525]

158. Lai Y, Yue Y, Bostick B \& Duan D in Muscle Gene Therapy (ed. Duan D) 205-218 (Springer, 2010).

159. Duan D, Yue Y \& Engelhardt JF Expanding AAV packaging capacity with trans-splicing or overlapping vectors: a quantitative comparison. Mol. Ther 4, 383-391 (2001). [PubMed: 11592843]

160. Lai $Y$ et al. Efficient in vivo gene expression by trans-splicing adeno-associated viral vectors. Nat. Biotechnol 23, 1435-1439 (2005). [PubMed: 16244658]

161. Ghosh A, Yue Y, Lai Y \& Duan D A hybrid vector system expands adeno-associated viral vector packaging capacity in a transgene-independent manner. Mol. Ther 16, 124-130 (2008). [PubMed: 17984978]

162. Aranko AS, Wlodawer A \& Iwai H Nature's recipe for splitting inteins. Protein Eng. Des. Sel 27, 263-271 (2014). [PubMed: 25096198]

163. Li J, Sun W, Wang B, Xiao X \& Liu XQ Protein trans-splicing as a means for viral vectormediated in vivo gene therapy. Hum. Gene Ther 19, 958-964 (2008). [PubMed: 18788906]

164. Truong DJ et al. Development of an intein-mediated split-Cas9 system for gene therapy. Nucleic Acids Res. 43, 6450-6458 (2015). [PubMed: 26082496]

165. Chew WL et al. A multifunctional AAV-CRISPR-Cas9 and its host response. Nat. Methods 13, 868-874 (2016). [PubMed: 27595405]

166. Yang $\mathrm{Y}$ et al. A dual AAV system enables the Cas9-mediated correction of a metabolic liver disease in newborn mice. Nat. Biotechnol 34, 334-338 (2016). [PubMed: 26829317]

167. Suzuki $\mathrm{K}$ et al. In vivo genome editing via CRISPR/Cas9 mediated homology-independent targeted integration. Nature 540, 144-149 (2016). [PubMed: 27851729]

168. Brown A, Li J, Zhu Y, Su Q \& Gao G rAAV-mediated nuclease-assisted vector integration (rAAVNAVI) promotes highly efficient and stable transgene expression in somatic tissues. Mol. Ther 26, S434 (2018).

169. Barzel A et al. Promoterless gene targeting without nucleases ameliorates haemophilia B in mice. Nature 517, 360-364 (2015). [PubMed: 25363772]

170. Borel F et al. Survival advantage of both human hepatocyte xenografts and genome-edited hepatocytes for treatment of alpha-1 antitrypsin deficiency. Mol. Ther 25, 2477-2489 (2017). [PubMed: 29032169]

171. Russell DW \& Hirata RK Human gene targeting by viral vectors. Nat. Genet 18, 325-330 (1998). [PubMed: 9537413]

172. Hagedorn $\mathrm{C}$ et al. S/MAR element facilitates episomal long-term persistence of adeno-associated virus vector genomes in proliferating cells. Hum. Gene Ther 28, 1169-1179 (2017). [PubMed: 28665147]

173. Piechaczek C, Fetzer C, Baiker A, Bode J \& Lipps HJ A vector based on the SV40 origin of replication and chromosomal S/MARs replicates episomally in CHO cells. Nucleic Acids Res. 27, 426-428 (1999). [PubMed: 9862961]

174. Kattenhorn LM et al. Adeno-associated virus gene therapy for liver disease. Hum. Gene Ther 27 , 947-961 (2016). [PubMed: 27897038] 
175. Wang D, Zhong L, Nahid MA \& Gao G The potential of adeno-associated viral vectors for gene delivery to muscle tissue. Expert Opin. Drug Deliv 11, 345-364 (2014). [PubMed: 24386892]

176. Bass-Stringer $\mathrm{S}$ et al. Adeno-associated virus gene therapy: translational progress and future prospects in the treatment of heart failure. Heart Lung Circ. 27, 1285-1300 (2018). [PubMed: 29703647]

177. Hocquemiller M, Giersch L, Audrain M, Parker S \& Cartier N Adeno-associated virus-based gene therapy for CNS diseases. Hum. Gene Ther 27, 478-496 (2016). [PubMed: 27267688]

178. Deverman BE, Ravina BM, Bankiewicz KS, Paul SM \& Sah DWY Gene therapy for neurological disorders: progress and prospects. Nat. Rev. Drug Discov 17, 641-659 (2018). [PubMed: 30093643] This is an up-to-date review on the current trends and challenges for AAV-based CNS gene therapy.

179. Petit L, Khanna H \& Punzo C Advances in gene therapy for diseases of the eye. Hum. Gene Ther 27, 563-579 (2016). [PubMed: 27178388]

180. Bennett J Taking stock of retinal gene therapy: looking back and moving forward. Mol. Ther 25 , 1076-1094 (2017). [PubMed: 28391961] This is an excellent review written from the perspective of an eyewitness account that details the experimental challenges, critical benchmarks and scientists that played key roles in developing AAV-based retinal gene therapies.

181. Auricchio A, Smith AJ \& Ali RR The future looks brighter after 25 years of retinal gene therapy. Hum. Gene Ther 28, 982-987 (2017). [PubMed: 28825330]

182. Russell S et al. Efficacy and safety of voretigene neparvovec (AAV2-hRPE65v2) in patients with RPE65-mediated inherited retinal dystrophy: a randomised, controlled, open-label, phase 3 trial. Lancet 390, 849-860 (2017). [PubMed: 28712537] This key report summarizes the phase III clinical trial findings for the now FDA-approved and European Medicines Agency-approved drug voretigene neparvovec (AAV2-hRPE65v2), trade name Luxturna.

183. Foust KD et al. Intravascular AAV9 preferentially targets neonatal neurons and adult astrocytes. Nat. Biotechnol 27, 59-65 (2009). [PubMed: 19098898]

184. Duque $\mathrm{S}$ et al. Intravenous administration of self-complementary AAV9 enables transgene delivery to adult motor neurons. Mol. Ther 17, 1187-1196 (2009). [PubMed: 19367261]

185. Zhang $\mathrm{H}$ et al. Several rAAV vectors efficiently cross the blood-brain barrier and transduce neurons and astrocytes in the neonatal mouse central nervous system. Mol. Ther 19, 1440-1448 (2011). [PubMed: 21610699]

186. Yang B et al. Intravasuclar delivery of rAAVRH.8 generates widespreading transduction of neuronal and glial cell types in the adult mouse central nervous system. Mol. Ther 20, S203 (2012).

187. Foust KD et al. Rescue of the spinal muscular atrophy phenotype in a mouse model by early postnatal delivery of SMN. Nat. Biotechnol 28, 271-274 (2010). [PubMed: 20190738]

188. Foust KD et al. Therapeutic AAV9-mediated suppression of mutant SOD1 slows disease progression and extends survival in models of inherited ALS. Mol. Ther 21, 2148-2159 (2013). [PubMed: 24008656]

189. Borel $\mathrm{F}$ et al. Therapeutic rAAVrh10 mediated SOD1 silencing in adult SOD1(G93A) mice and nonhuman primates. Hum. Gene Ther 27, 19-31 (2016). [PubMed: 26710998]

190. Ahmed SS et al. A single intravenous rAAV injection as late as P20 achieves efficacious and sustained CNS Gene therapy in Canavan mice. Mol. Ther 21, 2136-2147 (2013). [PubMed: 23817205]

191. Weismann CM et al. Systemic AAV9 gene transfer in adult GM1 gangliosidosis mice reduces lysosomal storage in CNS and extends lifespan. Hum. Mol. Genet 24, 4353-4364 (2015). [PubMed: 25964428]

192. Fu H, Dirosario J, Killedar S, Zaraspe K \& McCarty DM Correction of neurological disease of mucopolysaccharidosis IIIB in adult mice by rAAV9 trans-blood-brain barrier gene delivery. Mol. Ther 19, 1025-1033 (2011). [PubMed: 21386820]

193. Mendell JR et al. Single-dose gene-replacement therapy for spinal muscular atrophy. N. Engl. J. Med 377, 1713-1722 (2017). [PubMed: 29091557] 
194. Burnett JR \& Hooper AJ Alipogene tiparvovec, an adeno-associated virus encoding the Ser(447)X variant of the human lipoprotein lipase gene for the treatment of patients with lipoprotein lipase deficiency. Curr. Opin. Mol. Ther 11, 681-691 (2009). [PubMed: 20072945]

195. Borel F, Kay MA \& Mueller C Recombinant AAV as a platform for translating the therapeutic potential of RNA interference. Mol. Ther 22, 692-701 (2014). [PubMed: 24352214]

196. Xie J et al. Short DNA hairpins compromise recombinant adeno-associated virus genome homogeneity. Mol. Ther 25, 1363-1374 (2017). [PubMed: 28462820] This report reveals that vector designs harbouring strong secondary structure in the form of hairpins serve as scaffolds for genome truncation events during vector packaging.

197. Xie J, Tai PW, Brown A, Li C \& Gao G A novel rAAV-amiRNA platform enables potent in vivo gene silencing and a ten-fold enhancement of on-target specificity over conventional shRNA vectors. Mol. Ther 26, 436 (2018).

198. Abudayyeh OO et al. RNA targeting with CRISPR-Cas13. Nature 550, 280-284 (2017). [PubMed: 28976959]

199. Konermann $\mathrm{S}$ et al. Transcriptome engineering with RNA-targeting type VI-D CRISPR effectors. Cell 173, 665-676 (2018). [PubMed: 29551272]

200. Thakore PI et al. RNA-guided transcriptional silencing in vivo with $S$. aureus CRISPR-Cas9 repressors. Nat. Commun 9, 1674 (2018). [PubMed: 29700298]

201. Wang D et al. Adenovirus-mediated somatic genome editing of Pten by CRISPR/Cas9 in mouse liver in spite of Cas9-specific immune responses. Hum. Gene Ther 26, 432-442 (2015). [PubMed: 26086867]

202. Hynes AP et al. Widespread anti-CRISPR proteins in virulent bacteriophages inhibit a range of Cas9 proteins. Nat. Commun 9, 2919 (2018). [PubMed: 30046034]

203. Jessup $M$ et al. Calcium upregulation by percutaneous administration of gene therapy in cardiac disease (CUPID): a phase 2 trial of intracoronary gene therapy of sarcoplasmic reticulum $\mathrm{Ca}^{2+}$ ATPase in patients with advanced heart failure. Circulation 124, 304-313 (2011). [PubMed: 21709064]

204. Pepin D et al. AAV9 delivering a modified human Mullerian inhibiting substance as a gene therapy in patient-derived xenografts of ovarian cancer. Proc. Natl Acad. Sci. USA 112, E4418E4427 (2015). [PubMed: 26216943]

205. Johnson PR et al. Vector-mediated gene transfer engenders long-lived neutralizing activity and protection against SIV infection in monkeys. Nat. Med 15, 901-906 (2009). [PubMed: 19448633]

206. Balazs AB et al. Antibody-based protection against HIV infection by vectored immunoprophylaxis. Nature 481, 81-84 (2012).

207. Balazs AB \& West AP Jr. Antibody gene transfer for HIV immunoprophylaxis. Nat. Immunol 14, 1-5 (2013). [PubMed: 23238748]

208. Gardner MR et al. AAV-expressed eCD4-Ig provides durable protection from multiple SHIV challenges. Nature 519, 87-91 (2015). [PubMed: 25707797]

209. Limberis MP et al. Intranasal antibody gene transfer in mice and ferrets elicits broad protection against pandemic influenza. Sci. Transl Med 5, 187ra172 (2013).

210. Fuchs SP et al. AAV-delivered antibody mediates significant protective effects against SIVmac239 challenge in the absence of neutralizing activity. PLOS Pathog. 11, e1005090 (2015). [PubMed: 26248318]

211. Ding Q et al. Permanent alteration of PCSK9 with in vivo CRISPR-Cas9 genome editing. Circ. Res 115, 488-492 (2014). [PubMed: 24916110]

212. Wang L et al. Meganuclease targeting of PCSK9 in macaque liver leads to stable reduction in serum cholesterol. Nat. Biotechnol 36, 717-725 (2018). [PubMed: 29985478]

213. Bakondi B et al. In Vivo CRISPR/Cas9 gene editing corrects retinal dystrophy in the S334ter-3 rat model of autosomal dominant retinitis pigmentosa. Mol. Ther 24, 556-563 (2016). [PubMed: 26666451]

214. Yin $\mathrm{H}$ et al. Genome editing with Cas9 in adult mice corrects a disease mutation and phenotype. Nat. Biotechnol 32, 551-553 (2014). [PubMed: 24681508] 
215. Yin $\mathrm{H}$ et al. Therapeutic genome editing by combined viral and non-viral delivery of CRISPR system components in vivo. Nat. Biotechnol 34, 328-333 (2016). [PubMed: 26829318]

216. Song CQ et al. In vivo genome editing partially restores alpha1-antitrypsin in a murine model of AAT deficiency. Hum. Gene Ther 29, 853-860 (2018). [PubMed: 29597895]

217. Shen $\mathrm{S}$ et al. Amelioration of alpha-1 antitrypsin deficiency diseases with genome editing in transgenic mice. Hum. Gene Ther 29, 861-873 (2018). [PubMed: 29641323]

218. Li H et al. In vivo genome editing restores haemostasis in a mouse model of haemophilia. Nature 475, 217-221 (2011). [PubMed: 21706032]

219. Anguela XM et al. Robust ZFN-mediated genome editing in adult hemophilic mice. Blood 122, 3283-3287 (2013). [PubMed: 24085764]

220. Sharma R et al. In vivo genome editing of the albumin locus as a platform for protein replacement therapy. Blood 126, 1777-1784 (2015). [PubMed: 26297739]

221. Long $\mathrm{C}$ et al. Postnatal genome editing partially restores dystrophin expression in a mouse model of muscular dystrophy. Science 351, 400-403 (2016). [PubMed: 26721683]

222. Nelson CE et al. In vivo genome editing improves muscle function in a mouse model of Duchenne muscular dystrophy. Science 351, 403-407 (2016). [PubMed: 26721684]

223. Tabebordbar M et al. In vivo gene editing in dystrophic mouse muscle and muscle stem cells. Science 351, 407-411 (2016). [PubMed: 26721686]

224. Amoasii L et al. Gene editing restores dystrophin expression in a canine model of Duchenne muscular dystrophy. Science 362, 86-91 (2018). [PubMed: 30166439] This study is among the first to demonstrate the feasibility of AAV-based platforms to deliver CRISPR-Cas9 components in vivo to restore gene function, specifically dystrophin expression in a canine DMD model.

225. Wang D et al. Cas9-mediated allelic exchange repairs compound heterozygous recessive mutations in mice. Nat. Biotechnol 36, 839-842 (2018). [PubMed: 30102296]

226. Rees HA \& Liu DR Base editing: precision chemistry on the genome and transcriptome of living cells. Nat. Rev. Genet 19, 770-788 (2018). [PubMed: 30323312]

227. Clement N \& Grieger JC Manufacturing of recombinant adeno-associated viral vectors for clinical trials. Mol. Ther. Methods Clin. Dev 3, 16002 (2016). [PubMed: 27014711]

228. Gao G \& Sena-Esteves M in Molecular Cloning (eds Green MR \& Sambrook JR) 1209-1330 (Cold Spring Harbor Laboratory Press, 2012).

229. Grieger JC, Soltys SM \& Samulski RJ Production of recombinant adeno-associated virus vectors using suspension HEK293 Cells and continuous harvest of vector from the culture media for GMP FIX and FLT1 clinical vector. Mol. Ther 24, 287-297 (2016). [PubMed: 26437810]

230. Thorne BA, Takeya RK \& Peluso RW Manufacturing recombinant adeno-associated viral vectors from producer cell clones. Hum. Gene Ther 20, 707-714 (2009). [PubMed: 19848592]

231. Schnodt M \& Buning H Improving the quality of adeno-associated viral vector preparations: the challenge of product-related impurities. Hum. Gene Ther. Methods 28, 101-108 (2017). [PubMed: 28322595] This 'Methods' article comprehensively highlights the importance of identifying and limiting impurities in AAV vector preparations.

232. Burnham $B$ et al. Analytical ultracentrifugation as an approach to characterize recombinant adeno-associated viral vectors. Hum. Gene Ther. Methods 26, 228-242 (2015). [PubMed: 26414997]

233. Pierson EE, Keifer DZ, Asokan A \& Jarrold MF Resolving adeno-associated viral particle diversity with charge detection mass spectrometry. Anal. Chem 88, 6718-6725 (2016). [PubMed: 27310298]

234. De BP et al. In vivo potency assay for adeno-associated virus-based gene therapy vectors using AAVrh.10 as an example. Hum. Gene Ther. Methods 29, 146-155 (2018). [PubMed: 29706115]

235. Couto L, Buchlis G, Farjo R \& High KA Potency assay for AAV vector encoding retinal pigment epithelial 65 protein. Invest. Ophthalmol. Vis. Sci 57, 12 (2016). [PubMed: 26746014]

236. Drouin LM, Ciatto C \& Horowitz E Evaluation of a biological potency assay for an AAV2. AADC vector used in the treatment of Parkinson's disease. Mol. Ther 26, 418 (2018).

237. Buck TM et al. AAV serotype testing on cultured human donor retinal explants. Methods Mol. Biol 1715, 275-288 (2018). [PubMed: 29188521] 
238. Orlans HO, Edwards TL, De Silva SR, Patricio MI \& MacLaren RE Human retinal explant culture for ex vivo validation of AAV gene therapy. Methods Mol. Biol 1715, 289-303 (2018). [PubMed: 29188522]

239. Saveliev A et al. Accurate and rapid sequence analysis of adeno-associated virus plasmids by Illumina next-generation sequencing. Hum. Gene Ther. Methods 29, 201-211 (2018). [PubMed: 30051733]

240. Lecomte E et al. Advanced characterization of DNA molecules in rAAV vector preparations by single-stranded virus next-generation sequencing. Mol. Ther. Nucleic Acids 4, e260 (2015). [PubMed: 26506038]

241. Tai PWL et al. Adeno-associated virus genome population sequencing achieves full vector genome resolution and reveals human-vector chimeras. Mol. Ther. Methods Clin. Dev 9, 130141 (2018). [PubMed: 29766023]

242. Tai PWL et al. Heterogeneic genome encapsidation of rAAV-CRISPR/Cas9 vectors underscores potential limitations for promising in vivo gene-editing platforms. Mol. Ther 26, S167 (2018).

243. Gigout L et al. Altering AAV tropism with mosaic viral capsids. Mol. Ther 11, 856-865 (2005). [PubMed: 15922956]

244. Pacouret S et al. AAV-ID: a rapid and robust assay for batch-to-batch consistency evaluation of AAV preparations. Mol. Ther 25, 1375-1386 (2017). [PubMed: 28427840]

245. Bennett A et al. Thermal stability as a determinant of AAV serotype identity. Mol. Ther. Methods Clin. Dev 6, 171-182 (2017). [PubMed: 28828392]

246. Rayaprolu V et al. Comparative analysis of adeno-associated virus capsid stability and dynamics. J. Virol 87, 13150-13160 (2013). [PubMed: 24067976]

247. Vandamme C, Adjali O \& Mingozzi F Unraveling the complex story of immune responses to AAV Vectors trial after trial. Hum. Gene Ther 28, 1061-1074 (2017). [PubMed: 28835127]

248. Mingozzi F \& High KA Overcoming the host immune response to adeno-associated virus gene delivery vectors: the race between clearance, tolerance, neutralization, and escape. Annu. Rev. Virol 4, 511-534 (2017). [PubMed: 28961410] This review details the current challenges for efficacious AAV-based gene therapies, focusing specifically on overcoming host immunological responses.

249. Manno CS et al. Successful transduction of liver in hemophilia by AAV-Factor IX and limitations imposed by the host immune response. Nat. Med 12, 342-347 (2006). [PubMed: 16474400] This investigation highlights the importance of immunological responses against the AAV capsid and consequent loss of transgene expression over time despite successful transduction of the target tissue.

250. Louis Jeune V, Joergensen JA, Hajjar RJ \& Weber T Pre-existing anti-adeno-associated virus antibodies as a challenge in AAV gene therapy. Hum. Gene Ther. Methods 24, 59-67 (2013). [PubMed: 23442094]

251. Samaranch L et al. Adeno-associated virus serotype 9 transduction in the central nervous system of nonhuman primates. Hum. Gene Ther 23, 382-389 (2012). [PubMed: 22201473]

252. Gray SJ, Nagabhushan Kalburgi S, McCown TJ \& Jude Samulski R Global CNS gene delivery and evasion of anti-AAV-neutralizing antibodies by intrathecal AAV administration in nonhuman primates. Gene Ther 20, 450-459 (2013). [PubMed: 23303281]

253. Monteilhet V et al. A 10 patient case report on the impact of plasmapheresis upon neutralizing factors against adeno-associated virus (AAV) types 1, 2, 6, and 8. Mol. Ther 19, 2084-2091 (2011). [PubMed: 21629225]

254. Chicoine LG et al. Plasmapheresis eliminates the negative impact of AAV antibodies on microdystrophin gene expression following vascular delivery. Mol. Ther 22, 338-347 (2014). [PubMed: 24196577]

255. Mingozzi $\mathrm{F}$ et al. Overcoming preexisting humoral immunity to AAV using capsid decoys. Sci. Transl Med 5, 194ra192 (2013).

256. Nathwani AC et al. Adenovirus-associated virus vector-mediated gene transfer in hemophilia B. N. Engl. J. Med 365, 2357-2365 (2011). [PubMed: 22149959]

257. Nathwani AC et al. Long-term safety and efficacy of factor IX gene therapy in hemophilia B. N. Engl. J. Med 371, 1994-2004 (2014). [PubMed: 25409372] 
258. Petry $\mathrm{H}$ et al. Effect of viral dose on neutralizing antibody response and transgene expression after AAV1 vector re-administration in mice. Gene Ther. 15, 54-60 (2008). [PubMed: 17960164]

259. Corti $\mathrm{M}$ et al. Evaluation of readministration of a recombinant adeno-associated virus vector expressing acid alpha-glucosidase in Pompe disease: preclinical to clinical planning. Hum. Gene Ther. Clin. Dev 26, 185-193 (2015). [PubMed: 26390092]

260. Maldonado RA et al. Polymeric synthetic nanoparticles for the induction of antigen-specific immunological tolerance. Proc. Natl Acad. Sci. USA 112, E156-E165 (2015). [PubMed: 25548186]

261. Kishimoto TK et al. Improving the efficacy and safety of biologic drugs with tolerogenic nanoparticles. Nat. Nanotechnol 11, 890-899 (2016). [PubMed: 27479756]

262. Meliani A et al. Antigen-selective modulation of AAV immunogenicity with tolerogenic rapamycin nanoparticles enables successful vector re-administration. Nat. Commun 9, 4098 (2018). [PubMed: 30291246]

263. Mingozzi F et al. CD8(+) T cell responses to adeno-associated virus capsid in humans. Nat. Med 13, 419-422 (2007). [PubMed: 17369837]

264. Flotte TR \& Buning H Severe toxicity in nonhuman primates and piglets with systemic high-dose administration of adeno-associated virus serotype 9-like vectors: putting patients first. Hum. Gene Ther 29, 283-284 (2018). [PubMed: 29378415]

265. Mueller $\mathrm{C}$ et al. Human Treg responses allow sustained recombinant adeno-associated virusmediated transgene expression. J. Clin. Invest 123, 5310-5318 (2013). [PubMed: 24231351]

266. Biswas M, Kumar SRP, Terhorst C \& Herzog RW Gene therapy with regulatory T cells: a beneficial alliance. Front. Immunol 9, 554 (2018). [PubMed: 29616042]

267. Mendell JR et al. Dystrophin immunity in Duchenne's muscular dystrophy. N. Engl. J. Med 363, 1429-1437 (2010). [PubMed: 20925545]

268. Mingozzi $\mathrm{F}$ et al. Induction of immune tolerance to coagulation factor IX antigen by in vivo hepatic gene transfer. J. Clin. Invest 111, 1347-1356 (2003). [PubMed: 12727926]

269. Dobrzynski E et al. Induction of antigen-specific CD4+T cell anergy and deletion by in vivo viral gene transfer. Blood 104, 969-977 (2004). [PubMed: 15105293]

270. Cao $\mathrm{O}$ et al. Induction and role of regulatory $\mathrm{CD} 4+\mathrm{CD} 25+\mathrm{T}$ cells in tolerance to the transgene product following hepatic in vivo gene transfer. Blood 110, 1132-1140 (2007). [PubMed: 17438084]

271. Doerfler PA et al. Copackaged AAV9 vectors promote simultaneous immune tolerance and phenotypic correction of Pompe disease. Hum. Gene Ther 27, 43-59 (2016). [PubMed: 26603344]

272. Hinderer C et al. Neonatal systemic AAV induces tolerance to CNS gene therapy in MPS I dogs and nonhuman primates. Mol. Ther 23, 1298-1307 (2015). [PubMed: 26022732]

273. Rogers GL et al. Innate immune responses to AAV vectors. Front. Microbiol 2, 194 (2011).This is an important review that highlights the significance of innate immunity against the AAV vector genome via TLR-MYD88 activation.

274. Martino AT et al. The genome of self-complementary adeno-associated viral vectors increases Toll-like receptor 9-dependent innate immune responses in the liver. Blood 117, 6459-6468 (2011). [PubMed: 21474674]

275. Faust SM et al. CpG-depleted adeno-associated virus vectors evade immune detection. J. Clin. Invest 123, 2994-3001 (2013). [PubMed: 23778142]

276. Chan YK et al. Engineering AAV vectors to evade innate immune and inflammatory responses. Mol. Ther 26, S457 (2018).

277. Clark KR, Voulgaropoulou F, Fraley DM \& Johnson PR Cell lines for the production of recombinant adeno-associated virus. Hum. Gene Ther 6, 1329-1341 (1995). [PubMed: 8590738]

278. Gao GP et al. High-titer adeno-associated viral vectors from a Rep/Cap cell line and hybrid shuttle virus. Hum. Gene Ther 9, 2353-2362 (1998). [PubMed: 9829534]

279. Flotte TR et al. Phase 2 clinical trial of a recombinant adeno-associated viral vector expressing alpha1-antitrypsin: interim results. Hum. Gene Ther 22, 1239-1247 (2011). [PubMed: 21609134] 
280. Thomas DL et al. Scalable recombinant adeno-associated virus production using recombinant herpes simplex virus type 1 coinfection of suspension-adapted mammalian cells. Hum. Gene Ther 20, 861-870 (2009). [PubMed: 19419276]

281. Clement N, Knop DR \& Byrne BJ Large-scale adeno-associated viral vector production using a herpesvirus-based system enables manufacturing for clinical studies. Hum. Gene Ther 20, 796 806 (2009). [PubMed: 19569968]

282. Kondratov O et al. Direct head-to-head evaluation of recombinant adeno-associated viral vectors manufactured in human versus insect cells. Mol. Ther 25, 2661-2675 (2017). [PubMed: 28890324]

283. Mietzsch M et al. OneBac 2.0: Sf9 cell lines for production of AAV1, AAV2, and AAV8 vectors with minimal encapsidation of foreign DNA. Hum. Gene Ther. Methods 28, 15-22 (2017). [PubMed: 28125901]

284. Kotin RM Large-scale recombinant adeno-associated virus production. Hum. Mol. Genet 20, R2R6 (2011). [PubMed: 21531790]

285. Penaud-Budloo $\mathrm{M}$ et al. Accurate identification and quantification of DNA species by nextgeneration sequencing in adeno-associated viral vectors produced in insect cells. Hum. Gene Ther. Methods 28, 148-162 (2017). [PubMed: 28463571]

286. Qu W, Wang M, Wu Y \& Xu R Scalable downstream strategies for purification of recombinant adeno-associated virus vectors in light of the properties. Curr. Pharm. Biotechnol 16, 684-695 (2015). [PubMed: 25941887]

287. Qu G et al. Separation of adeno-associated virus type 2 empty particles from genome containing vectors by anion-exchange column chromatography. J. Virol. Methods 140, 183-192 (2007). [PubMed: 17196264]

288. Lock M, Alvira MR \& Wilson JM Analysis of particle content of recombinant adeno-associated virus serotype 8 vectors by ion-exchange chromatography. Hum. Gene Ther. Methods 23, 56-64 (2012). [PubMed: 22428980]

289. Nass SA et al. Universal method for the purification of recombinant AAV vectors of differing serotypes. Mol. Ther. Methods Clin. Dev 9, 33-46 (2018). [PubMed: 29349097]

290. Donsante A et al. AAV vector integration sites in mouse hepatocellular carcinoma. Science 317 , 477 (2007). [PubMed: 17656716] Although the consensus has shifted since its publication, this study is the first to demonstrate that AAV integration into the mouse Rian locus can upregulate proximal non-coding RNAs, leading to hepatocellular carcinoma.

291. Wang PR et al. Induction of hepatocellular carcinoma by in vivo gene targeting. Proc. Natl Acad. Sci. USA 109, 11264-11269 (2012). [PubMed: 22733778]

292. Zhong L et al. Recombinant adeno-associated virus integration sites in murine liver after ornithine transcarbamylase gene correction. Hum. Gene Ther 24, 520-525 (2013). [PubMed: 23621841]

293. $\mathrm{Li} \mathrm{H}$ et al. Assessing the potential for AAV vector genotoxicity in a murine model. Blood 117 , 3311-3319 (2011). [PubMed: 21106988]

294. Chandler RJ, LaFave MC, Varshney GK, Burgess SM \& Venditti CP Genotoxicity in mice following AAV gene delivery: a safety concern for human gene therapy? Mol. Ther 24, 198-201 (2016). [PubMed: 26906613]

295. Chandler RJ et al. Vector design influences hepatic genotoxicity after adeno-associated virus gene therapy. J. Clin. Invest 125, 870-880 (2015). [PubMed: 25607839]

296. Gil-Farina I et al. Recombinant AAV integration is not associated with hepatic genotoxicity in nonhuman primates and patients. Mol. Ther 24, 1100-1105 (2016). [PubMed: 26948440]

297. Kaeppel C et al. A largely random AAV integration profile after LPLD gene therapy. Nat. Med 19, 889-891 (2013). [PubMed: 23770691]

298. Buning H \& Schmidt M Adeno-associated vector toxicity-to be or not to be? Mol. Ther 23, 16731675 (2015). [PubMed: 26606658]

299. Srivastava A \& Carter BJ AAV infection: protection from cancer. Hum. Gene Ther 28, 323-327 (2017). [PubMed: 27832705]

300. Emery DW, Yannaki E, Tubb J \& Stamatoyannopoulos G A chromatin insulator protects retrovirus vectors from chromosomal position effects. Proc. Natl Acad. Sci. USA 97, 9150-9155 (2000). [PubMed: 10908661] 
301. Liu M et al. Genomic discovery of potent chromatin insulators for human gene therapy. Nat. Biotechnol 33, 198-203 (2015). [PubMed: 25580597]

302. Hermonat PL \& Muzyczka N Use of adeno-associated virus as a mammalian DNA cloning vector: transduction of neomycin resistance into mammalian tissue culture cells. Proc. Natl Acad. Sci. USA 81, 6466-6470 (1984). [PubMed: 6093102]

303. Tratschin JD, West MH, Sandbank T \& Carter BJ A human parvovirus, adeno-associated virus, as a eucaryotic vector: transient expression and encapsidation of the procaryotic gene for chloramphenicol acetyltransferase. Mol. Cell. Biol 4, 2072-2081 (1984). [PubMed: 6095038]

304. Samulski RJ, Chang LS \& Shenk T A recombinant plasmid from which an infectious adenoassociated virus genome can be excised in vitro and its use to study viral replication. J. Virol 61, 3096-3101 (1987). [PubMed: 3041032] This study is among the first to report cloning of the AAV genome into plasmids for the purposes of characterizing AAV replication.

305. McLaughlin SK, Collis P, Hermonat PL \& Muzyczka N Adeno-associated virus general transduction vectors: analysis of proviral structures. J. Virol 62, 1963-1973 (1988). [PubMed: 2835501]

306. Samulski RJ, Chang LS \& Shenk T Helper-free stocks of recombinant adeno-associated viruses: normal integration does not require viral gene expression. J. Virol 63, 3822-3828 (1989). [PubMed: 2547998]

307. Flotte TR et al. Stable in vivo expression of the cystic fibrosis transmembrane conductance regulator with an adeno-associated virus vector. Proc. Natl Acad. Sci. USA 90, 10613-10617 (1993). [PubMed: 7504271]

308. Kaplitt MG et al. Long-term gene expression and phenotypic correction using adeno-associated virus vectors in the mammalian brain. Nat. Genet 8, 148-154 (1994). [PubMed: 7842013] This report is among the first to demonstrate that rAAVs can transduce cells of the CNS in vivo, hallmarking the potential for rAAVs as viable gene therapy vectors.

309. Flotte T et al. A phase I study of an adeno-associated virus-CFTR gene vector in adult CF patients with mild lung disease. Hum. Gene Ther 7, 1145-1159 (1996). [PubMed: 8773517] This study is the first clinical trial in humans for AAV-based gene therapy.

310. McCown TJ, Xiao X, Li J, Breese GR \& Samulski RJ Differential and persistent expression patterns of CNS gene transfer by an adeno-associated virus (AAV) vector. Brain Res. 713, 99107 (1996). [PubMed: 8724980]

311. Kessler PD et al. Gene delivery to skeletal muscle results in sustained expression and systemic delivery of a therapeutic protein. Proc. Natl Acad. Sci. USA 93, 14082-14087 (1996). [PubMed: 8943064] This report demonstrates the potential for AAV-based therapeutic transgene delivery to the muscle and for transformed muscle tissue as a viable target for ectopic expression of secreted proteins.

312. Xiao X, Li J \& Samulski RJ Efficient long-term gene transfer into muscle tissue of immunocompetent mice by adeno-associated virus vector. J. Virol 70, 8098-8108 (1996). [PubMed: 8892935] This is the first publication that demonstrates successful long-term in vivo transduction of mammalian muscles by rAAVs.

313. Hauswirth WW et al. Treatment of leber congenital amaurosis due to RPE65 mutations by ocular subretinal injection of adeno-associated virus gene vector: short-term results of a phase I trial. Hum. Gene Ther 19, 979-990 (2008). [PubMed: 18774912] References 313, 314 and 315 encompass a series of hallmark studies in human patients with LCA who were treated with rAAV2-hRPE65 vectors and showed improvement in visual sensitivity.

314. Bainbridge JW et al. Effect of gene therapy on visual function in Leber's congenital amaurosis. N. Engl. J. Med 358, 2231-2239 (2008). [PubMed: 18441371]

315. Cideciyan AV et al. Human gene therapy for RPE65 isomerase deficiency activates the retinoid cycle of vision but with slow rod kinetics. Proc. Natl Acad. Sci. USA 105, 15112-15117 (2008). [PubMed: 18809924] 


\section{Vectorology}

A field of study based on the bioengineering of delivery vehicles for biomolecules such as DNA and rNA. 


\section{Packaging}

The biological process of producing fully assembled vector particles, such as recombinant adeno-associated viruses (rAAVs) consisting of the DNA genome within the capsid. 


\section{Serotypes}

A classification system for capsids or viral strains established by surface antigens. 


\section{Episomal DNA}

DNA that is autonomous from the host chromosomal DNA; the term is used for circularized, double-stranded adeno-associated virus (AAV) vector genome species that persist within the transduced cell nucleus. 


\section{Blood-brain barrier}

(BBB). A semipermeable physiological barrier that separates the circulating blood from the central nervous system and comprises endothelial cells, astrocytes and pericytes. 


\section{Seroepidemiological}

Pertaining to the epidemiological study of blood serum antibodies or antigens in populations. 


\section{Codon expansion}

A synthetic biology technique that reprogrammes a codon to encode an amino acid that is not naturally encoded. 


\section{Intraparenchymal}

Within the bulk of the tissue or organ. 


\section{Artificial microRNAs}

(amirs). Molecular tools that are based on natural microrNA sequences and structures that house a small interfering rNA (sirNA) cassette designed to target a desired sequence. 


\section{Homology-directed repair}

(HDr). A DNA repair mechanism in the presence of a homologous DNA piece as the repair template. 


\section{Multiplicity of infection}

The ratio of infectious agents (for example, recombinant adeno-associated virus (rAAV)) to infection targets (for example, cells). 


\section{Non-homologous end joining}

(NHeJ). A DNA repair mechanism that directly ligates two broken DNA ends without a homologous DNA template. 


\section{Adventitious agents}

Any potentially harmful and unintentionally introduced agent (viruses, bacteria, mycoplasma, fungi, protozoa, parasites, transmissible spongiform encephalopathies, etc.) that may be found in manufactured drug products. 


\section{Genotoxicity}

Damaging effect on the genome, whereby deleterious mutations are created. 


\section{Epigenome}

The combined chromatin state (for example, DNA and histone modifications and noncoding rNA associations) throughout the genome of an organism that imparts heritable influence over gene expression. 


\section{Box 1 |}

\section{rAAv manufacturing}

A popular recombinant adeno-associated virus (raav) production method involves triple transfection of HeK293 cells, which harbour constitutively expressed adenovirus (adv) E1a and E1b genes, with a trans-plasmid expressing rep and cap genes, a cis-plasmid to be packaged into adeno-associated virus (aav) capsids and a helper plasmid containing other adv genes that serve helper function, such as the $E 2 A, E 4$ and $V A$ rNa genes that are essential for replication, $\mathrm{mrNa}$ processing and translation, respectively 228 . Furthermore, HeK293 cells have been adapted for growth in suspension to allow for scale-up and increased production yields ${ }^{229}$.

HeLa cells stably transfected with copies of the aav rep-cap genes and the raav vector genome with flanking inverted terminal repeats (itrs) are a viable solution for large-scale production $^{277}$. with this platform, production is simply initiated by the introduction of adv. However, there are two drawbacks to this platform: a new producer cell line must be independently generated for each combination of capsid and transgene construct, and adv becomes an adventitious virus in the production workflow. adv can be heat inactivated by treating preparations for $0.5-1.0$ hour at $56{ }^{\circ} \mathrm{C}$ with little impact on raav stability and infectivity. alternatively, an adv-aav hybrid virus system (B50/hybrid) was developed to circumvent these two issues ${ }^{278}$.

replication-deficient herpes simplex virus (Hsv) can also serve as a helper platform and has been used to support large-scale rAAV production for clinical manufacturing 279,280 . the first clinical trial conducted with raav1 that was manufactured with recombinant Hsvs was launched in 2010 for a 1-antitrypsin deficiency. several Hsv and/or aav vector platforms have been developed for large-scale production throughout the years ${ }^{281}$.

Mammalian cell-free platforms have also been developed to address contaminating $\mathrm{DNa}$ sequences originating from packaging cell genomes. the most commonly utilized are based on recombinant baculoviruses, known as baculovirus expression vectors (Bevs) ${ }^{282,283}$. these Bevs are infected into Spodoptera frugiperda (sf9) insect cells for vector production. $\mathrm{sf} 9$ cells are amenable to expression of aav rep and cap and do not require additional helper viral genes beyond those provided by the $\mathrm{Bev}^{284}$. However, vectors generated from first-generation Bev-sf9 systems did demonstrate altered capsid compositions with reduced vP1 expression in a serotype-dependent manner, which resulted in lower transduction profiles ${ }^{283}$. advances in platform design to achieve proper capsid protein stoichiometries have improved vector potencies ${ }^{282}$. importantly, Bev-sf9 systems exhibit reduced encapsidation of contaminating DNas. using next-generation sequencing methods, less than $2.1 \%$ of reads were attributed to baculoviral $\mathrm{DNa}$, while sf9 host cell DNa was detected at $0.03 \%$ or less ${ }^{285}$. these improvements not only reduced foreign DNas but also increased full-to-empty particle ratios ${ }^{282}$.

Purification steps include collection of producer cells and supernatant, lysis of cellular material by chemical or mechanical means to liberate raav particles, enzymatic digestion to remove non-encapsidated $\mathrm{DNa}$ to reduce nucleic acid contaminants originating from upstream production steps and full particle isolation and concentration. a popular and 
robust method is caesium chloride $(\mathrm{CsCl})$ gradient sedimentation. this process relies on the generation of a $\mathrm{CsCl}$ density gradient that allows for the separation of empty, partially packaged and fully packaged viral particles ${ }^{228}$. above all, cellular debris, proteins and nucleic acids from lysates are separated. However, $\mathrm{CsCl}$ gradient centrifugation is somewhat laborious and time consuming. Purification by iodixanol gradient offers a simpler alternative, but the process yields vectors of lower purity. For research-grade, small-scale preparations, single or multiple rounds of ultracentrifugation can yield vectors with sufficient titres and purity. For large-scale production, multiple purification steps involving scalable chromatographic methods, such as affinity or ion exchange chromatography, are usually carried out ${ }^{286}$. recent advances in chromatography have allowed not only serotype-independent raav capture but also separation of fully packaged particles from empty capsids $229,287-289$. 


\section{Box 2 |}

\section{is vector genome integration associated with rAAv genotoxicity?}

among the most promising attributes for adeno-associated virus (aav) as a gene therapy vector are its low genotoxicity profile in humans and the lack of strong and direct evidence that recombinant aavs (raavs) can cause vector genome-mediated host genotoxicity in humans. the prevailing thought is raav genomes remain predominantly episomal. Yet, the most substantial challenge for aav-based gene therapy is arguably related to whether administration and long-term presence of raavs can result in genotoxicity through vector genome integration. the association between hepatocellular carcinoma (HCC) and aav vector integration was first reported in $2007\left(\right.$ REF. $\left.^{290}\right)$ and formally proved by homology-directed integration of vector genomes ${ }^{291}$. the precise mechanisms that drive integration are not fully known nor are they agreed on ${ }^{292,293}$. studies in cell culture models and in mice under specific conditions have demonstrated that raav genome integrations occur under high multiplicity of infection and exhibit preferential integration into the Rian genomic locus, a region that is unique to murine genomes ${ }^{294,295}$. these reports are now recognized as not relevant to clinical settings, as occurrence of $\mathrm{HCC}$ in mice following raav administration is due to vector genome integration into the murine-specific Rian locus and a subsequent upregulation of tumourdriver microrNas embedded within close proximity to integration sites ${ }^{294}$. importantly, studies in both patient samples (1 year after administration) and non-human primates (1 month after injection) show low rates of integration and absence of integration within proximity to known $\mathrm{HCC}$ driver genes ${ }^{296}$. an investigation into the integration capacity of raav1-LPL ${ }^{\mathrm{s} 447 \mathrm{X}}$ in patient muscle biopsy samples also revealed random integration and hot spots within only mitochondrial $\mathrm{DNa}^{297}$. Owing to the safety track record of raav in clinical trials and consensus within the field ${ }^{298,299}$, very little work has focused specifically on strategies to limit genotoxic integration events. Notwithstanding, the design of insulator elements to limit transactivation of nearby genes via a regulatory control cassette holds promise for mitigating genotoxic effects owing to spurious integration 300,301 . 


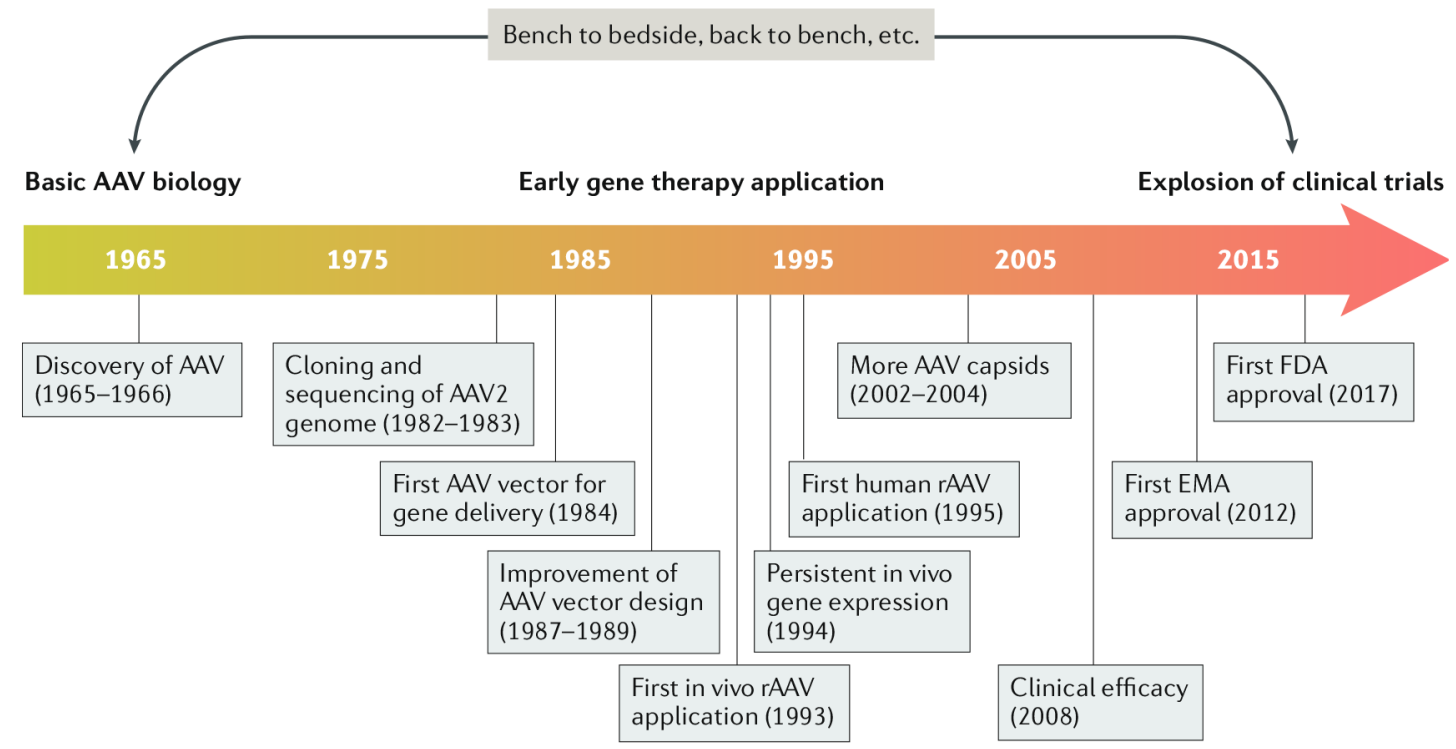

Fig. 1 |. 50 years of AAv.

A timeline is pictured showing selected key milestones in adeno-associated virus (AAV) gene therapy development. Following the first reports on the discovery of AAV in 1965 and 1966 (REFS $^{1,2}$ ), the next 15-20 years of basic biology research culminated in the cloning and sequencing of the AAV2 genome ${ }^{21-23}$. AAV was vectorized in 1984 for in vitro gene delivery $^{302,303}$, and the development of a trans-complementing system to produce highquality recombinant AAV (rAAV) in the late 1980s greatly facilitated the use of rAAV as a gene delivery vehicle ${ }^{304-306}$, leading to the first in vivo application ${ }^{307}$. Persistent gene expression by rAAVs in mammalian tissues was first reported in 1994 (REF. $^{308}$ ), followed by seminal publications in 1996 (REFS $^{309-312}$ ). An AAV vector was first used in a human patient in 1995 for the treatment of cystic fibrosis ${ }^{309}$. A new family of primate AAV serotypes was reported in the early 2000s, greatly expanding the AAV toolbox for in vivo gene delivery ${ }^{63-65}$. The efficacy of AAV gene therapy was convincingly demonstrated in 2008 for the treatment of Leber congenital amaurosis ${ }^{313-315}$. The first AAV-based gene therapy drug, Glybera, was approved by the European Medicines Agency (EMA) in 2012, with Luxturna becoming the first AAV gene therapy product to receive US Food and Drug Administration (FDA) approval 5 years later. We emphasize that early studies of the basic biology of AAV laid the foundation for vector development and therapeutic application. During the translation process, the application of AAV vectors for gene therapy delivery further stimulated interest in studying AAV biology. 


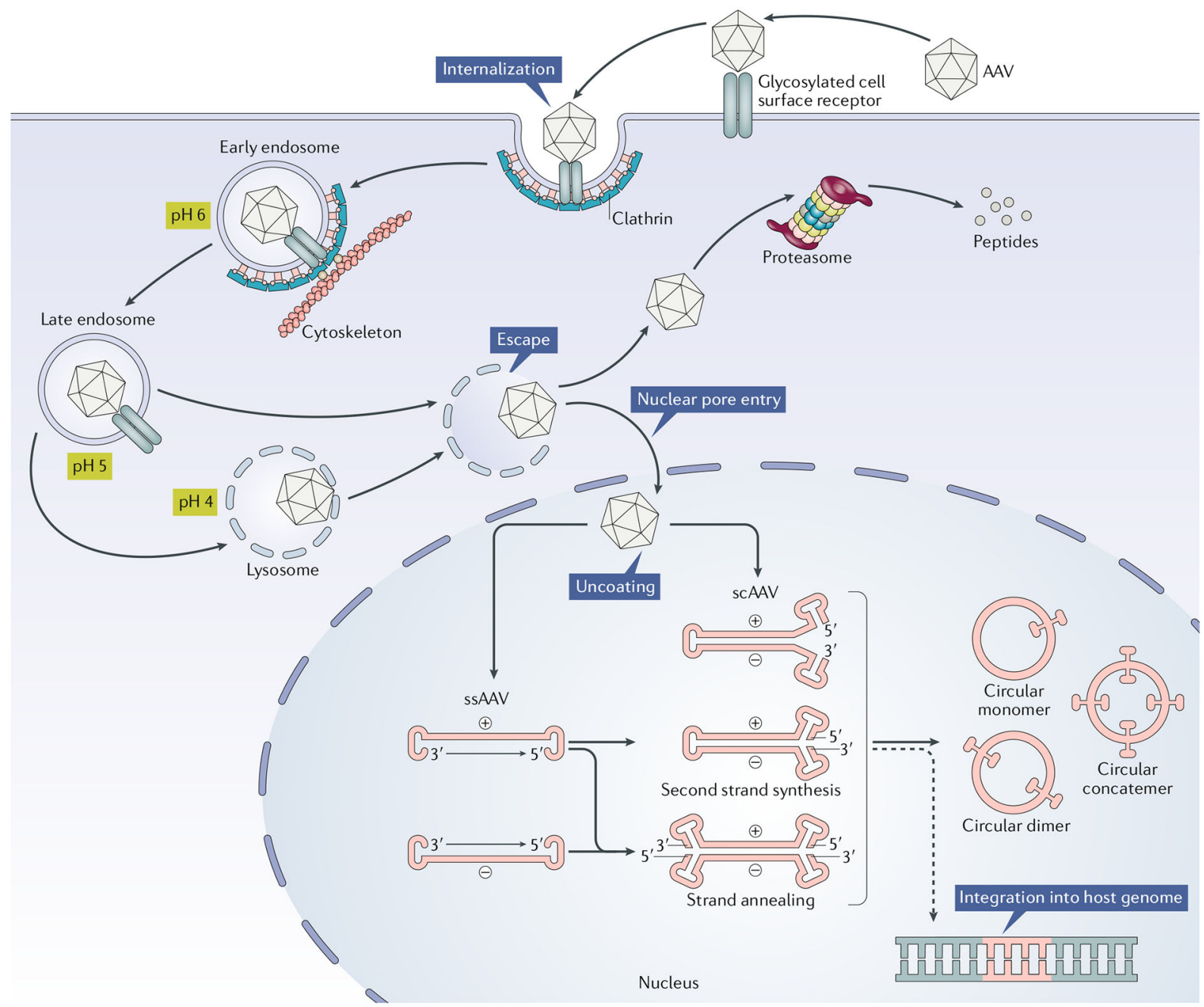

Fig. 2 |. Diagram of rAAv transduction pathway.

Adeno-associated virus (AAV) is recognized by glycosylated cell surface receptors of the host. This triggers internalization of the virus via clathrin-mediated endocytosis. AAV then traffics through the cytosol mediated by the cytoskeletal network. Owing to the somewhat low $\mathrm{pH}$ environment of the endosome, the VP1/VP2 region undergoes a conformational change. Following endosomal escape, AAV undergoes transport into the nucleus and uncoating. AAV can also undergo proteolysis by the proteasome. There are currently two classes of recombinant AAVs (rAAVs) in use: single-stranded AAV (ssAAV) and selfcomplementary AAV (scAAV). ssAAVs are packaged as either sense (plus-stranded) or antisense (minus-stranded) genomes. These single-stranded forms are still transcriptionally inert when they reach the nucleus and must be converted to double-stranded DNA as a prerequisite for transcription. This conversion can be achieved by second strand synthesis via host cell DNA polymerases or by strand annealing of the plus and minus strands that may coexist in the nucleus. Because scAAVs are already double-stranded by design, they can immediately undergo transcription. The viral inverted terminal repeats (ITRs) present in the rAAV genome can drive inter-molecular or intra-molecular recombination to form circularized episomal genomes that can persist in the nucleus. Vector genomes can also 
undergo integration into the host genome at very low frequencies, depicted by the dashed line (BOX 2). 


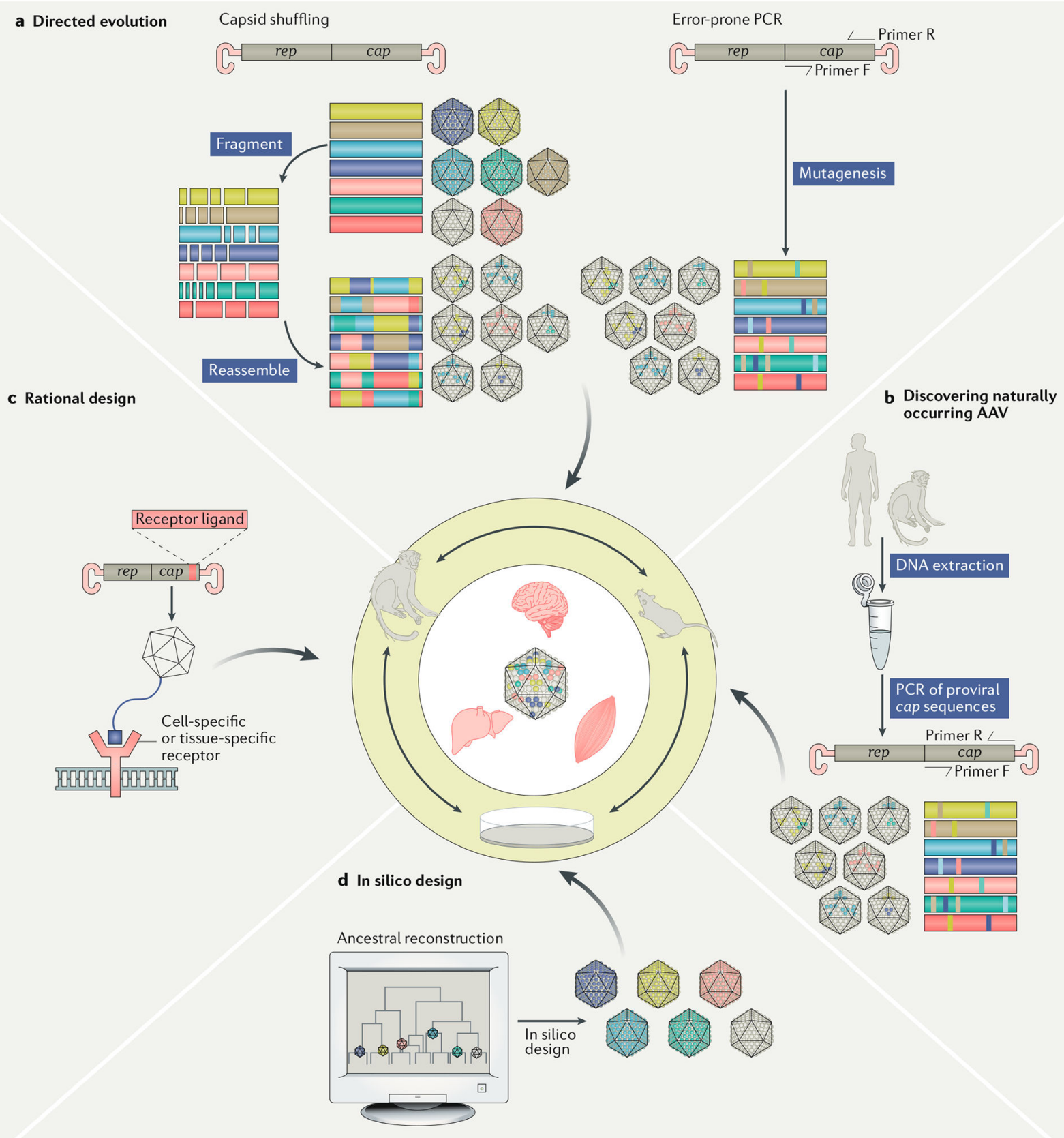

Fig. 3 |. infographic of the four primary methods for capsid discovery and engineering. a | Directed evolution via methods such as capsid shuffling or error-prone PCR can create numerous unique capsid combinations that may harbour distinct and favourable vector properties. $\mathbf{b} \mid$ Discovery of naturally occurring adeno-associated virus (AAV) surveys proviral sequences present in host tissues that may have been infected with wild-type AAVs. c | Rational design utilizes pre-existing knowledge of capsid biology and host cell targets to engineer capsids that specifically recognize tissue-specific or cell-specific extracellular markers or to evade immune surveillance. $\mathbf{d}$ | In silico design, a somewhat new method for capsid discovery, utilizes computational approaches to predict novel capsid designs that are 
not seen in nature. Reconstruction of ancestral AAVs from contemporary capsids is one form of in silico design. The inner circle depicts the primary methods for candidate capsid screening: in vitro (for example, cell culture) and in vivo using small animal models (for example, mice) and large animal models (for example, non-human primates) that serve as proxies for the human patient. 


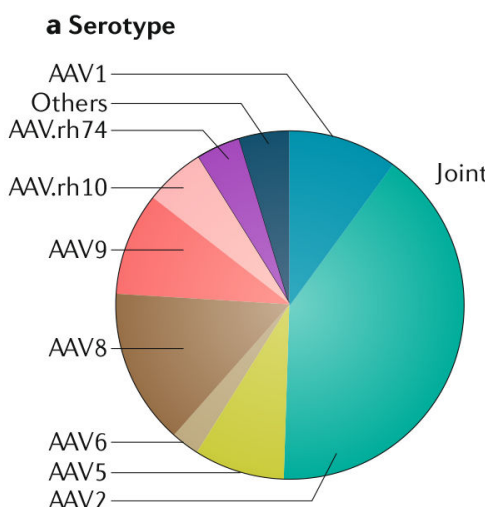

b Primary target

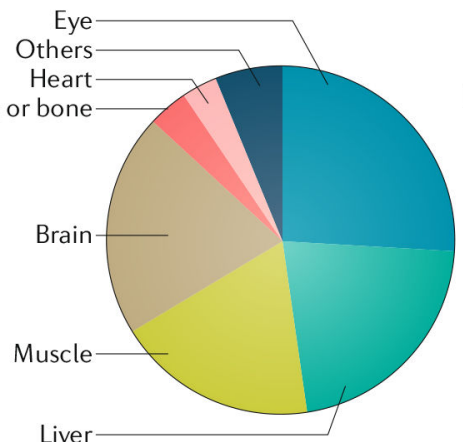

c Phase

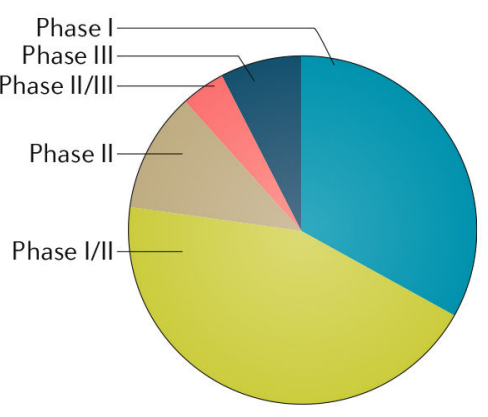

Fig. 4 . overview of rAAv interventional gene therapy clinical trials.

The data set is from ClinicalTrials.gov, accessed on 13 November 2018. The 145 registered trials are categorized on the basis of adeno-associated virus (AAV) capsid serotype (part a), primary tissue target for gene delivery (part b) and clinical trial phase (part c). rAAV, recombinant AAV. 


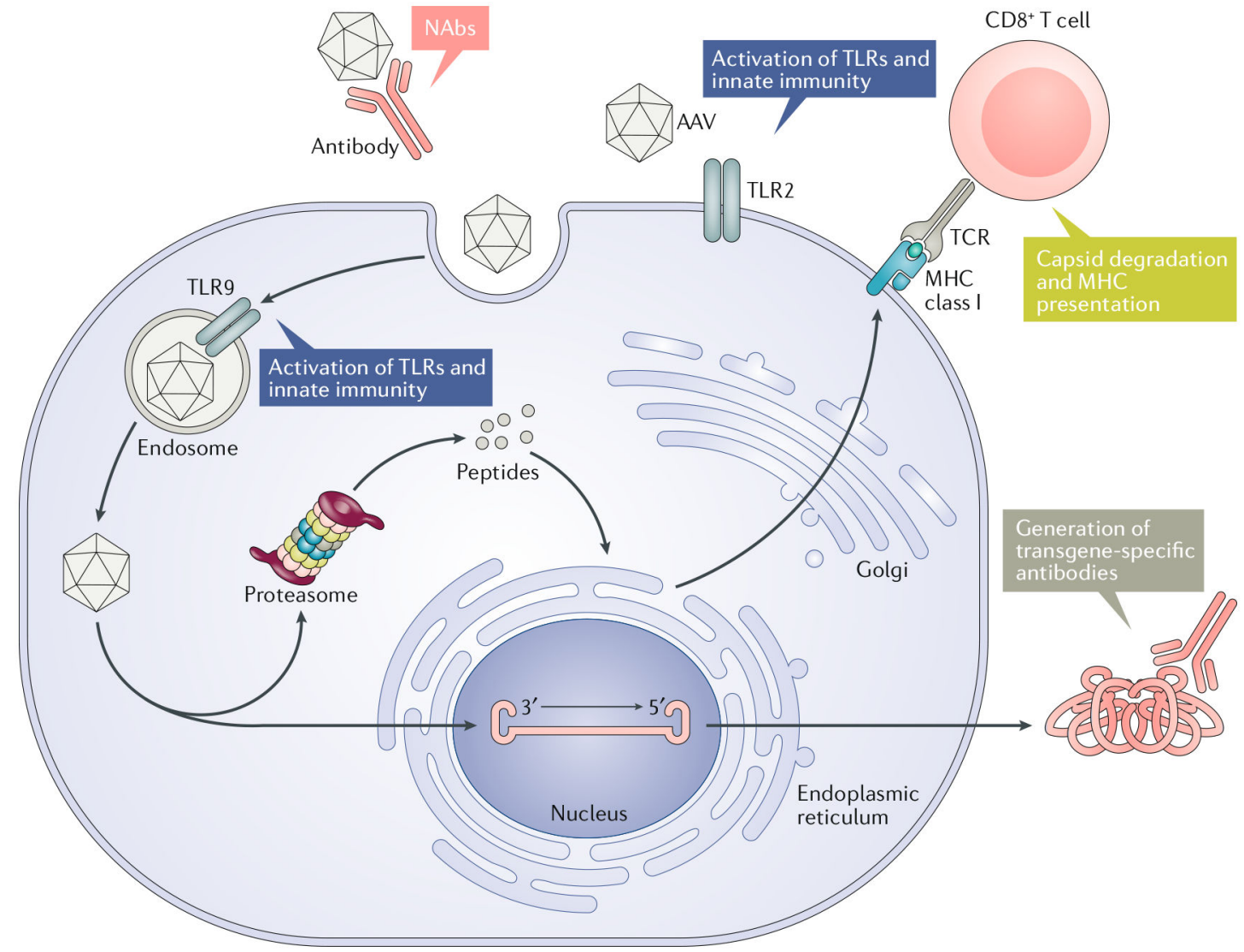

Fig. 5 |. immunological barriers to successful rAAv gene delivery.

The recombinant adeno-associated virus (rAAV) may encounter neutralizing antibodies (NAbs) that are widely found in the human population, which greatly compromises gene delivery, especially following intravascular administration. Furthermore, administration of rAAV can induce capsid-specific NAb generation (not shown). The rAAV capsid and genome may trigger innate immunity via activation of Toll-like receptor 2 (TLR2) and TLR9, respectively. Activation of innate immunity can further promote adaptive immune responses. The capsid undergoes proteasomal degradation, and the resulting peptides are presented by major histocompatibility complex (MHC) class I molecules to $\mathrm{CD}^{+} \mathrm{T}$ cells. The $\mathrm{CD}^{+} \mathrm{T}$ cell can exert destructive cytotoxic effects to eliminate rAAV-transduced cells, resulting in the loss of transgene expression. The transgene product can elicit a humoral immune response to generate transgene product-specific antibodies that can compromise therapeutic efficacy. AAV, adeno-associated virus. 


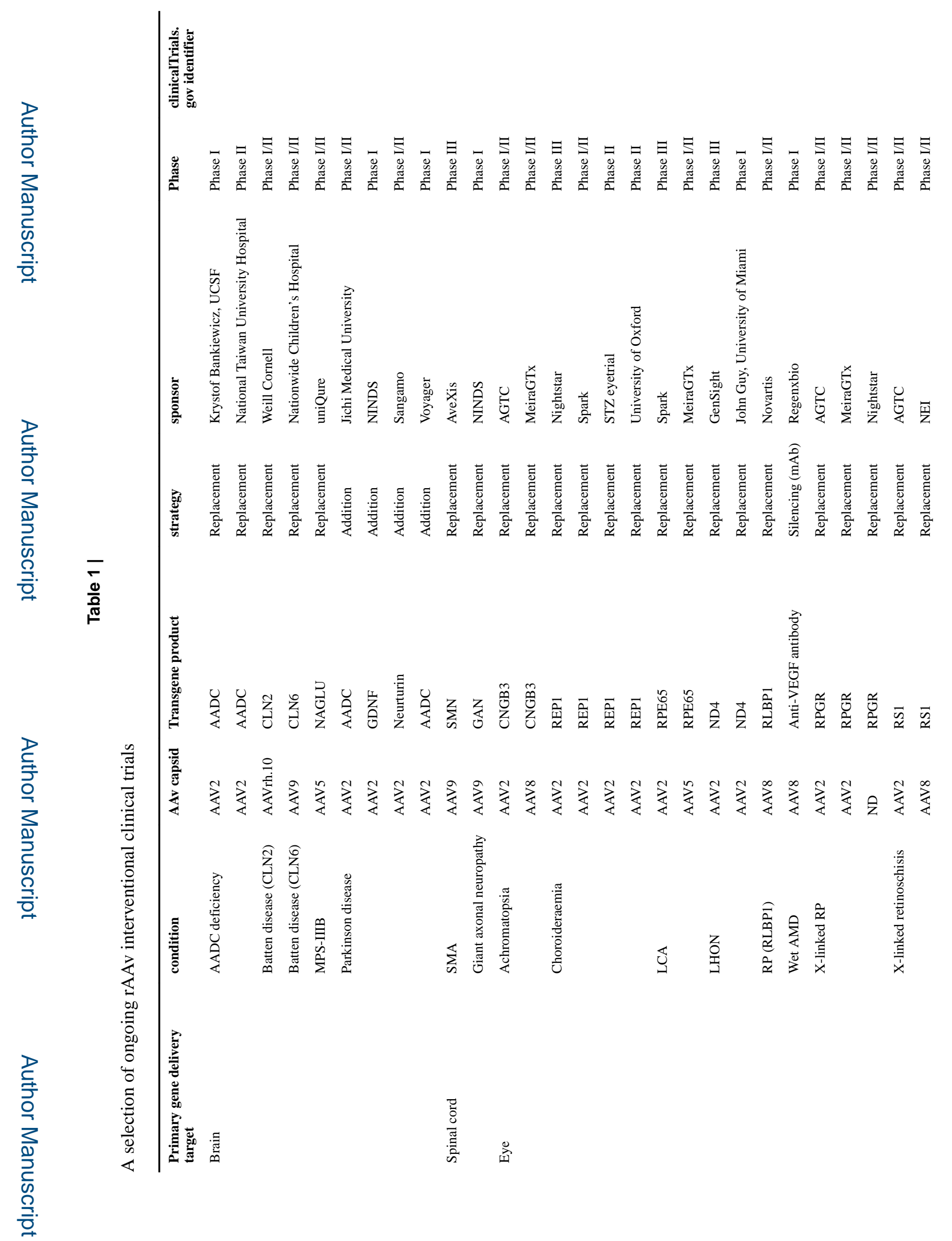

Nat Rev Drug Discov. Author manuscript; available in PMC 2019 December 23. 
Wang et al.

Page 60

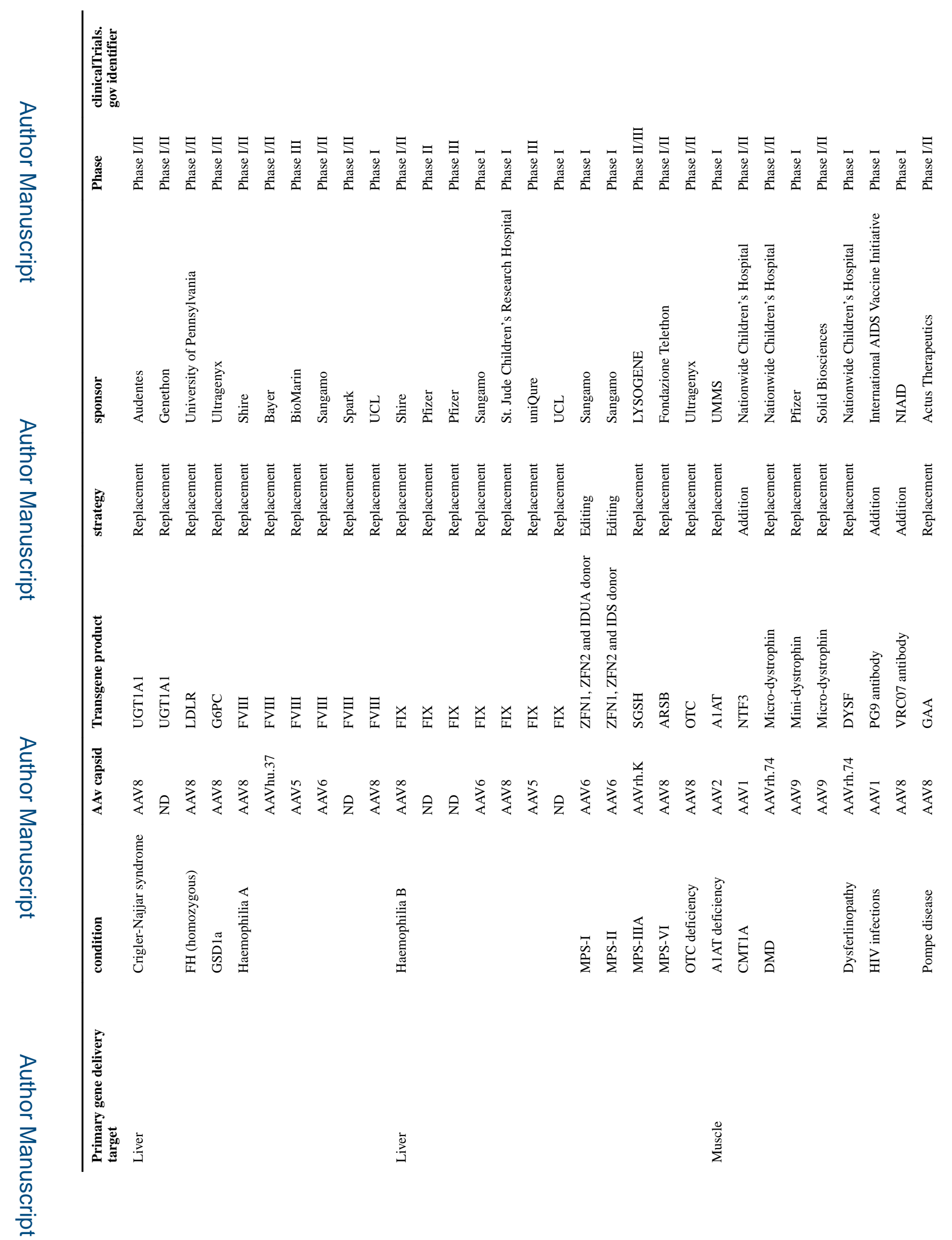

Nat Rev Drug Discov. Author manuscript; available in PMC 2019 December 23. 
Wang et al.

Page 61

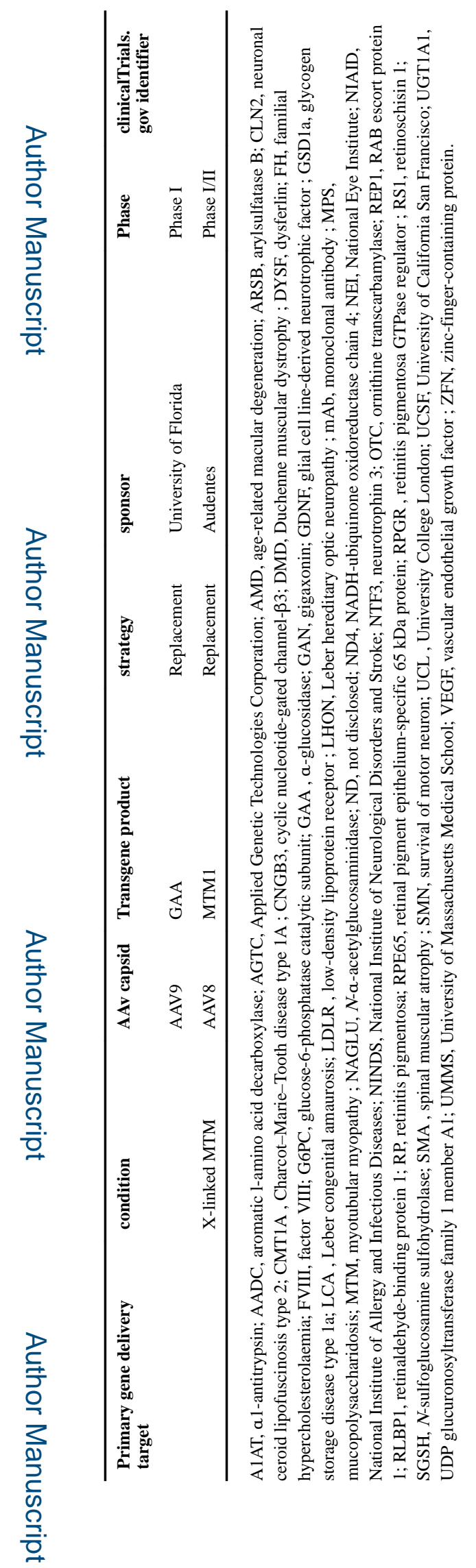

Nat Rev Drug Discov. Author manuscript; available in PMC 2019 December 23. 